Ready to Reform: How Popular Initiatives Can Be Successful

Katharina Eva Hofer, Christian Marti, Monika Bütler June 2015 Discussion Paper no. 2014-19 


$\begin{array}{ll}\text { Editor: } & \text { Martina Flockerzi } \\ & \text { University of St.Gallen } \\ & \text { School of Economics and Political Science } \\ & \text { Department of Economics } \\ & \text { Bodanstrasse 8 } \\ & \text { CH-9000 St. Gallen } \\ & \text { Phone } \quad+41712242325 \\ & \text { Fax } \quad+41712243135 \\ & \text { Email seps@unisg.ch } \\ & \text { School of Economics and Political Science } \\ & \text { Department of Economics } \\ & \text { University of St.Gallen } \\ & \text { Bodanstrasse } 8 \\ \text { Publisher: } & \text { CH-9000 St. Gallen } \\ & \text { Phone +41 71 224 23 25 } \\ & \text { Fax }+41712243135 \\ & \text { http://www.seps.unisg.ch }\end{array}$




\title{
Ready to Reform: How Popular Initiatives Can Be Successful ${ }^{1}$
}

\author{
Katharina Eva Hofer, Christian Marti, Monika Bütler
}

Authors' address:

Katharina Eva Hofer, Christian Marti, Monika Bütler

Swiss Institute for Empirical Economic Research (SEW-HSG)

Varnbüelstrasse 14

$\mathrm{CH}-9000$ St.Gallen

Phone +41712242320

Fax $\quad+41712242302$

Email_katharina.hofer@unisg.ch

christian.marti@unisg.ch

monika.buetler@unisg.ch

Website www.sew.unisg.ch

\footnotetext{
${ }^{1}$ For valuable comments, we thank Sergio Galletta, Roland Hodler, Antonio Merlo, Christoph Moser, Daniel Ochsner, Adam Pigon, and Andreas Steinmayr, as well as participants at the Meeting of the European Public Choice Society (Zürich, 2013), the Meeting of the Australasian Public Choice Society (Singapore, 2013), Sinergia Workshop of the Swiss National Science Foundation (September 2014, Zürich), CESifo Workshop on Political Economy (Dresden, 2014), Young Swiss Economist Meeting (Zürich, 2015), Meeting of the European Public Choice Society (Groningen, 2015), and seminar participants at the University of Pennsylvania, the University of St.Gallen, and the University of Adelaide.
} 


\begin{abstract}
We study whether the number of signatures collected to qualify a popular initiative affects the probability of reforming the status quo. The initiative process is modeled as a sequential game under uncertainty: petitioners make an entry decision and collect signatures to qualify the initiative. Politicians decide about a political compromise - a counter proposal - after which petitioners have the option to withdraw the initiative before the vote. In equilibrium, politicians infer the initiative's popularity from the number of signatures and collection time. The more the initiative is perceived as a threat to the status quo, the more likely politicians come up with a counter proposal. Under certain conditions, petitioners have the incentive to collect more signatures than required for qualification to demonstrate high success probability.

We test model predictions using the data set of all Swiss constitutional initiatives at federal level between 1891 and 2010. Overall, we find supporting evidence for the model mechanisms. Fast signature collection is associated with a higher probability of changing the status quo. The reason is that initiatives collecting signatures quickly are more likely to provoke a compromise than slow collectors. Ultimately, counter proposal are key to amending the status quo. Interestingly, we find that restricting signature collection time and increasing the signature requirement, reduces the informative mechanism of the signature collection process considerably.
\end{abstract}

\title{
Keywords
}

Direct Democracy; Popular Initiative; Voting; Common Learning.

\section{JEL Classification}

D72, P16. 


\section{Introduction}

In representative democracies the voters' main channel to influence politics is via the election and potential reelection of politicians. Direct democratic institutions offer additional ways to challenge the existing policies or propose new measures. Such institutions are deeply rooted in many U.S. states and Switzerland, and constitutional provisions for direct democracy shape politics in a growing number of countries, predominantly at local and state level (Altman, 2010; LeDuc, 2003; Matsusaka, 2005). One direct democratic instrument, the popular initiative, enables citizens to propose policies themselves after successfully qualifying them for ballot by collecting enough signatures. ${ }^{1}$

This paper deals with the popular initiative process in a setting that allows for political compromise through so called counter proposals. ${ }^{2}$ When an initiative is voted against the status quo, citizens might accept the initiative if it comes closer to the median preferred policy than the status quo. Office-motivated politicians then incur reputational costs while ideologically motivated politicians receive disutility from moving away from their desired policies. Proposing a compromise might be a prudent alternative for both ideologically and office-motivated politicians: it can persuade petitioners to withdraw the initiative if the compromise is satisfactory. Or the counter proposal can win outright at the vote, thus preventing the initiative from winning. ${ }^{3}$ In some direct democracies like Switzerland, counter proposals constitute an institutionalized element of the initiative regulation. Similar provisions exist in a number of U.S. states like Washington, Maine, and Colorado, and at state and local level in several German states (Center for Direct Democracy, 2014; Initiative and Referendum Institute, 2014; More Democracy, 2014). ${ }^{4}$

At the time when politicians decide about a compromise, they require information about the initiative's popularity. We argue that the number of signatures collected to qualify the initiative can serve as indication for the initiative's winning probability. A large amount of signatures collected quickly can demonstrate popular approval, while a slow and hard collection probably reflects lower support among voters. Potentially, petitioners collect more signatures than required to endeavor

\footnotetext{
${ }^{1}$ Initiatives exist in around half of the U.S. states and in Switzerland (Initiative and Referendum Institute, 2014). Similar provisions have been introduced in most German states in the last two decades (Association for More Democracy, 2014) and for example in several Eastern European countries after the fall of communism (Center for Direct Democracy, 2014).

${ }^{2}$ E.g., in 1971 a Swiss association of women's rights activists demanded the legalization of abortion without any preconditions. The counter proposal stated that abortion should be legalized under certain conditions in the first weeks of pregnancy only.

${ }^{3}$ In some U.S. states politicians can put up new laws for popular vote, possibly at the same day as initiatives, as so called referred measures. This comes close to a formal counter proposal (Initiative and Referendum Institute, 2014): the legislature has the possibility to enact laws as alternatives parallel to the initiative process to demonstrate that some action is being taken on the subject.

${ }^{4}$ In a number of U.S. states, initiatives are dealt with in an indirect way. This means that the legislature can choose to approve the initiative, and it is only put to the popular vote in case the parliament rejects the initiative. This shares some similarities with a counter proposal as well. The indirect initiative is available in nine states for statutory proposals and in two states (Massachusetts and Mississippi) for constitutional amendments (Initiative and Referendum Institute, 2014).
} 
politicians to make a counter proposal.

We study this topic in a sequential initiative game with a signature collection stage and allowing for the possibility of counter proposals. In our model, both petitioners and politicians have symmetric information, but they are uncertain about the precise position of the median voter. During signature collection, information about the initiative's winning probability is revealed, thus reducing uncertainty. To qualify the initiative, petitioners have to collect at least a signature requirement but are free to collect more. Politicians decide about making a costly political compromise while updating their belief about the initiative's winning probability from the signature collection. Afterwards petitioners decide whether to withdraw the initiative before the vote.

The initiative game has a unique subgame perfect equilibrium in cutoff strategies. Maximizing their expected payoffs, petitioners collect signatures to either just qualify the initiative, or "overcollect" hoping to positively influence politicians' belief about the initiative's winning probability. Politicians are then more likely to compromise if they belief the initiative to be a real threat to the status quo. After a counter proposal the initiative is only withdrawn if the former is sufficiently close to the initiative.

Our model predicts a higher probability of reforming the status quo the faster the signature collection. The main explanation is that quick collectors more likely induce counter proposals, which in turn are key to changing the status quo. We test these hypotheses using all 249 Swiss federal initiatives that have completed the initiative process between 1891 and 2010.

The results confirm a positive relation between fast signature collection and the probability of reform. Also, collecting signatures quickly is related to a higher probability of receiving a counter proposal: by collecting many signatures within a short time period petitioners seem able to prove that their initiative enjoys high popular support. However, these relations cease to exist after collection time is restricted and the signature requirement doubled in 1978. This considerably reduces the variation in signatures and collection time and thus makes signatures a less informative channel for politicians to determine the initiative's probability of success. Irrespective of institutional influence, we find that change is most likely after a counter proposal was issued. If the initiative competes exclusively against the status quo at ballot, change is rarely observed.

We extend the literature on direct democratic models (cf. Matsusaka and McCarty (2001) for a referendum game). Our model shares some similarities with Gerber's (1996) initiative model. But our model is the first encompassing the qualification stage and the possibility of a counter proposal as decisive elements. Our paper is also related to the literature on the responsiveness of politics in direct democracies. Gerber and Lupia (2010) examine the effect of political competition on responsiveness. Fatke and Freitag (2013) find that popular initiatives serve as a substitute channel for other forms of political protest. Moreover, our research adds to the literature analyzing various effects of signatures collected to qualify the initiative: the effect of signature requirements on turnout (Barankay, Sciarini \& Trechsel, 2003), the motivational effect of petition signing on political knowledge (Neinman \& Gottdiener, 1982), on the probability of turning out (Boehmke \& Alvarez, 2014; Parry, Smith \& Henry, 2012; Schmid, 2013), and voting in favor of the initiative (Hofer, 2013). 
In Section 2 we describe the Swiss institutional setting and the major institutional changes to the initiative process. The model is developed, discussed and solved in Section 3. The data and empirical strategy are presented in Section 4, and the results follow in Section 5. Section 6 concludes.

\section{Institutional Background}

Direct democratic instruments come in two forms depending on who initiates the vote, top down (mandatory referendums regulated by constitution) or bottom up (optional referendums and initiatives proposed by citizens) (Altman, 2010). Our research focuses on Swiss federal initiatives at constitutional level. An initiative text is either a fully formulated constitutional article, or a general suggestion for a constitutional article to be concretized by the legislature. However, since there is more interpretation leeway for the parliament in the latter case, general suggestions occur relatively rarely. ${ }^{5}$ The popular initiative process has three stages (Frey, 1994): qualification, political, and voting stage. In the first qualification stage, petitioners, commonly referred to as initiative committees, collect a minimum requirement of signatures. The Swiss signature requirement is constant and not a percentage value of the active electorate as in California.

Upon successful qualification, at the political stage the two chambers of parliament ${ }^{6}$ decide whether or not to prepare a direct or indirect counter proposal. A direct counter proposal is at the constitutional level and has to be voted by the people. An indirect counter proposal is a law that does not need ratification from the voters. However, it might be subject to an optional referendum if enough signatures are collected opposing it. ${ }^{7}$ Petitioners may withdraw their initiative anytime during the political stage. This happens frequently after a counter proposal has been made. Initiatives can also be withdrawn for other reasons, such as a lack of funding or if it becomes apparent that the initiative has no popular support (Hofer, 2012).

At the voting stage, three different situations can occur. First, the initiative is on the ballot without a counter proposal. Second, if the initiative is withdrawn, only the counter proposal is voted. Third, both the initiative and the counter proposal are put to the vote simultaneously. It takes an absolute majority of the votes for the initiative or the counter proposal to come into force. The voting procedure for simultaneous votes of initiative and counter proposal changed in 1987: now it is possible to vote in favor of both initiative and counter proposal, and specify in a tie-breaking question which of the two is preferred. If both receive an absolute majority of votes, the tie-breaking question is decisive. In addition, the winning proposal also needs a majority of the Swiss cantons to approve it. The ballot system has a strong federal element: a change to the constitution must win a majority of the votes that are not concentrated in a few populous cantons.

\footnotetext{
${ }^{5}$ In Switzerland, no federal statutory initiatives exists. Cantons and municipalities have their own independent regulations regarding initiatives, but they are not considered here.

${ }^{6}$ The National Council represents the citizens in proportion to the size of cantons and vote share of parties, similar to the American House of Representatives. The Council of States represents the cantons (states), similar to the American Senate.

${ }^{7}$ In practice, very few indirect counter proposals are challenged by referenda. Indirect counter proposals tend to be a compromise of a broad parliamentarian majority and face little opposition.
} 
There were four further big institutional changes regarding the initiative process. First, while initiatives were initially not meant to be withdrawn, petitioners started withdrawing initiatives starting in 1928. Second, in 1951 the withdrawal practice was institutionalized and legally recorded. In 1971 women were given federal political rights such that they could sign and vote for initiatives. As a consequence, seven years later the signature requirement was increased from 50,000 to 100,000, and collection time restricted to 18 months.

\section{Model}

We model the initiative process as a sequential game in the spirit of the Swiss institutional setup. A main characteristic of the model is the politicians and petitioners' uncertainty about the initiative's winning probability. Petitioners collect signatures to reduce this uncertainty. Afterwards politicians decide whether to propose a compromise. Petitioners have the option to withdraw the initiative before the ballot.

We first describe the model, discuss the main model assumptions, and solve the equilibrium. In a second step we develop testable implications of the model.

\subsection{Model Setup}

Let $\mathrm{A}$ be the elected politicians in parliament and $\mathrm{B}$ the petitioners. The players are unitary actors ${ }^{8}$ and information is symmetric. Both the status quo $x_{q}$ and the initiative $x_{i}$ are located on the real line between zero and one as common in games of political economy (Downs, 1957; Black, 1958). They are exogenously given and observed by both players. Without loss of generality, we assume that $x_{q}<x_{i}$. Politicians have the option to make a counter proposal $x_{c}$ which is assumed to be a compromise between the current policy and the proposed initiative $x_{q}<x_{c}<x_{i}$.

There is a continuum of voters with single-peaked and symmetric preferences around their ideal points located on the real line. Ideal points are distributed on a probability function with a single peaked and symmetric density function. The shape of each density function is identical. Its position is determined by the median voter's position $\mu$ which is distributed on a uniform function with lower bound $\underline{\mu} \geq 0$ and upper bound $\bar{\mu} \leq 1$.

The winning probability of the status quo against the initiative is denoted by $\pi_{q}\left(x_{q}, x_{i}\right)$ with a corresponding vote share $v_{q}\left(x_{q}, x_{i}\right)$ (Osborne, 2000). The status quo wins against the initiative if it receives at least half the votes, i,e., if the median is closer to the status quo than to the initiative.

$$
\pi_{q}\left(x_{q}, x_{i}\right)=\operatorname{Prob}\left(v_{q}\left(x_{q}, x_{i}\right) \geq \frac{1}{2}\right)=\operatorname{Prob}\left(m \leq \frac{1}{2}\left(x_{q}+x_{i}\right)\right)=\frac{\frac{1}{2}\left(x_{q}+x_{i}\right)-\underline{\mu}}{\bar{\mu}-\underline{\mu}}
$$

It follows that the initiative wins with probability $\pi_{i}\left(x_{q}, x_{i}\right)=1-\pi_{q}\left(x_{q}, x_{i}\right)=\frac{\bar{\mu}-\frac{1}{2}\left(x_{q}+x_{i}\right)}{\bar{\mu}-\underline{\mu}}$. The ${ }^{8}$ Cf. Gerber (1996) for a thorough discussion of this assumption. 
winning probability of the status quo against the counter proposal is defined analogously. To ensure positive winning probabilities for all policy alternatives, we assume that $\underline{\mu} \leq x_{q}$ and $\bar{\mu} \geq x_{i}$. Then the outcome of the ballot is uncertain as no policy wins or loses with certainty. Potentially, a majority of voters prefers a more extreme policy than the status quo or the initiative.

With three policy alternatives at ballot, the initiative wins whenever the median is right to the middle point between the counter proposal and the initiative, with winning probability $\pi_{i}\left(x_{q}, x_{c}, x_{i}\right)=$ $\frac{\bar{\mu}-\frac{1}{2}\left(x_{c}+x_{i}\right)}{\bar{\mu}-\underline{\mu}}$. The counter proposal wins under two conditions: first, the median must be located in the interval $\left(\frac{1}{2}\left(x_{q}+x_{c}\right), \frac{1}{2}\left(x_{c}+x_{i}\right)\right)$. Second, the vote share must exceed half of the votes. ${ }^{9}$ The counter proposal's winning probability is independent of its precise position between status quo and initiative (proof in appendix), $\pi_{c}\left(x_{q}, x_{c}, x_{i}\right)=\frac{b}{\bar{\mu}-\underline{\mu}}$. The status quo's winning probability $\pi_{q}\left(x_{q}, x_{c}, x_{i}\right)=\frac{\frac{1}{2}\left(x_{c}+x_{i}\right)-\underline{\mu}-b}{\bar{\mu}-\underline{\mu}}$ follows directly. ${ }^{10}$

Players are uncertain about the initiative's winning probability because information about the median voter distribution's lower bound is incomplete. They know that the lower bound takes the highest possible value $\underline{\mu}^{h}=x_{q}$ with probability $p_{0} \in[0,1]$. Else it takes some lower value with equal probability. We refer to the former as high types, and low types to the latter. The players' initial belief is the expected value $\underline{\mu}_{0}=E_{0}[\underline{\mu}]=p_{0} * \underline{\mu}^{h}+\left(1-p_{0}\right) * \frac{1}{2} \underline{\mu}^{h}=\frac{1+p_{0}}{2} \underline{\mu}^{h}$.

To qualify an initiative for ballot, petitioners are required to collect $s_{t} \geq \bar{s}$ signatures where $\bar{s}$ denotes the legal requirement, and $s_{t}$ is the cumulative number of collected signatures at any time $t$. Time is continuous with $t \in[0, \infty)$. The signature collection is a publicly observed common learning process through which petitioners and politicians receive information about the median distribution. During collection, all petitioners continuously accumulate $s_{l}>0$ signatures. High types receive stochastic lump sums of additional signatures $s_{h}>0$, which arrive independently over time according to a Poisson process with intensity $\lambda$. During collection, costs of $\gamma$ continuously

Numerical Example Winning Probabilities: In Figure 1 the median voter is distributed between zero and one, $x_{q}=0.35$, and $x_{i}=0.85$ with the middle point $\frac{1}{2}\left(x_{q}+x_{i}\right)=0.6$. The initiative wins whenever the median voter is located in the interval $(0.6,1]$ represented by the dashed line because it is closer to the initiative than to the status quo. Consequently, the initiative wins with probability $\pi_{i}\left(x_{q}, x_{i}\right)=\frac{1-0.6}{1-0}=0.40$.

Fig. 1: Example of Winning Probabilities

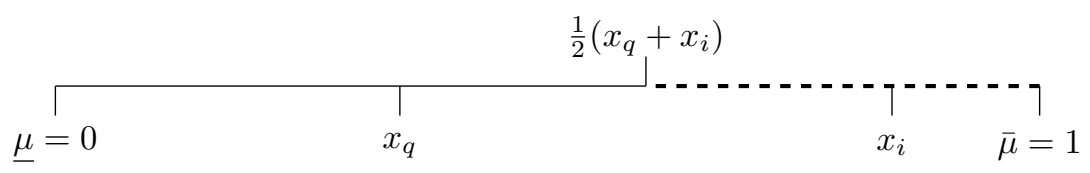

Note: Median distribution $\mu \sim U[0,1]$, status quo $x_{q}=0.35$, initiative $x_{i}=0.85$, and their middle point $\frac{1}{2}\left(x_{q}+x_{i}\right)=$ 0.6. The initiative wins when the median voter is located in the interval represented by the dashed line, which happens with probability $\pi_{i}\left(x_{q}, x_{i}\right)=0.4$.

\footnotetext{
${ }^{9}$ Supporters of the initiative and the counter proposal may cumulatively be in the majority. However, if none of them has the absolute majority of voters, the status quo remains in place.

${ }^{10}$ For the model, we use the original voting rule which was in place between 1891 and 1987 . The tie-breaking question was introduced afterwards.
} 
Fig. 2: Median Distribution's Lower Bound over Collection Time

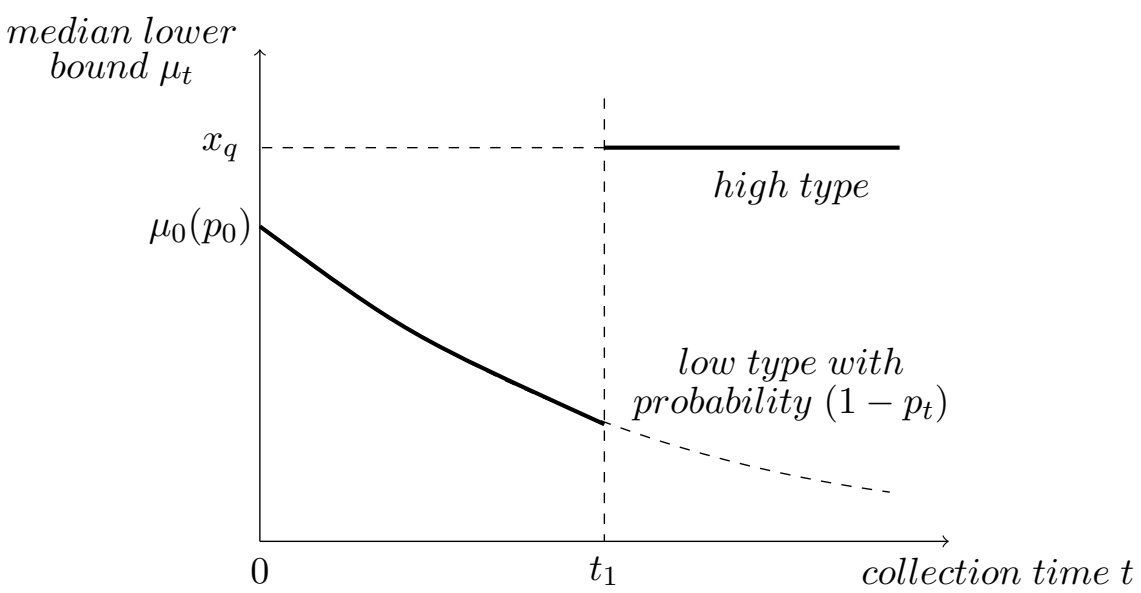

Note: The y-axis displays the belief about the median distribution's lower bound $\mu_{t}$ based probability of being a high type $p_{t}$, and the x-axis collection time. The belief of being a high type $p_{t}$ decreases with collection time if only low numbers of signatures $s_{l}$ are observed, and thus the belief about the median distribution's lower bound decreases. If a lump sum $s_{h}$ occurs e.g. at time $t_{1}$, the initiative is a high type with certainty and the median lower bound takes its highest possible value $\mu_{t}=x_{q}$.

accrue. Once collection stops, it cannot be resumed. ${ }^{11}$

Figure 2 shows an example of the belief about the median distribution's lower bound depending on the probability of being a high type $p_{t}$ as collection time evolves. At collection start at time $t=0$, the probability that the initiative is a high type is $p_{0}$ and the corresponding belief is $\mu_{0}\left(p_{0}\right)$. If no lump sum occurs during collection, the belief that the initiative is a high type decreases monotonically with time according to $\partial p_{t} / \partial t=-\lambda p_{t}\left(1-p_{t}\right)$ and converges to zero as time goes to infinity (Keller \& Rady, 2010). Accordingly, the expected belief about the median distribution $\underline{\mu}_{t}\left(p_{t}\right)=\frac{1+p_{t}}{2} \underline{\mu}^{h}$ decreases with $p_{t}$ : the longer petitioners collect without receiving a lump sum, the smaller is the initiative's winning probability perceived by the players. Suppose that a lump sum $s_{h}$ occurs at time $t_{1}$. Since only high types receive lump sums, players know that the initiative is a high type with certainty, and beliefs are irreversibly at $\underline{\mu}=x_{q}$. Then players also know that the initiative has the highest possible winning probability.

Politicians' utility depends on the winning policy. The initiative is their least preferred policy and yields utility $U_{i}^{A}=0$. Utility increases linearly with the distance between the winning policy and the initiative: $U_{c}^{A}=x_{i}-x_{c}$ is the utility if the counter proposal wins, and $U_{q}^{A}=x_{i}-x_{q}$ if the status quo wins. Politicians pay a reputation loss of size $r$ if they make a counter proposal that loses against the status quo at ballot. With this assumption we rule out strategic compromises

\footnotetext{
${ }^{11}$ The signature collection process resembles the optimal experimentation strategy of a single decision maker in Strulovici (2010): the petitioners are a single player deciding whether to continue experimentation (signature collection), or to stop the process. The main difference is that players in Strulovici (2010) receive payoffs during experimentation and also once experimentation has stopped. In our model, petitioners receive one of two possible expected payoffs and then the game stops.
} 
Fig. 3: Extensive-Form Game Tree of Initiative Game

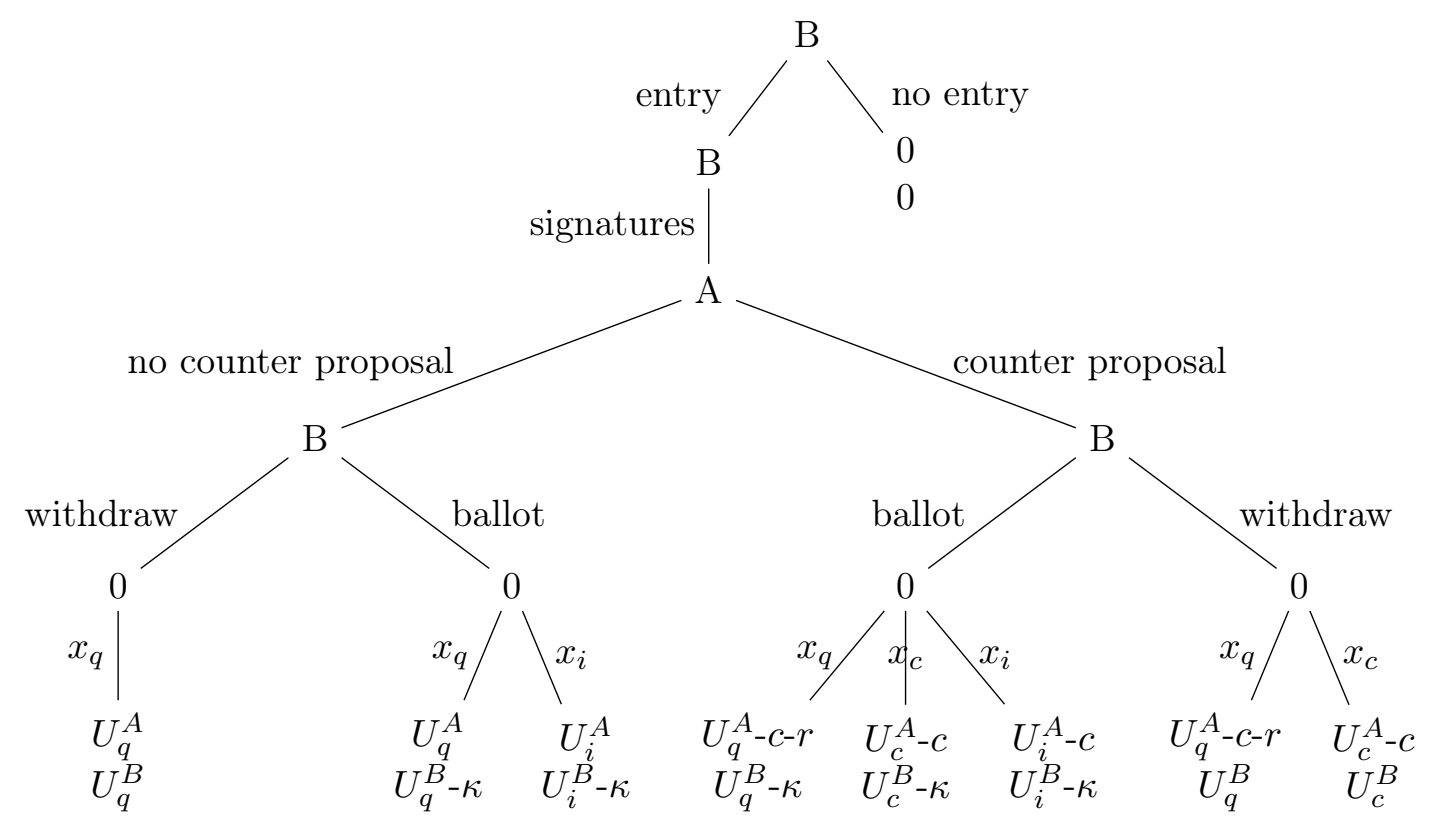

exclusively designed to steal votes from the initiative to help the status quo win. ${ }^{12}$ If politicians make a counter proposal, costs $c$ incur. They reflect the politicians' time and effort to debate the details of the counter proposal in parliament.

Politicians and petitioners have symmetric utility functions. They are rewarded least if the status quo remains in place, $U_{q}^{B}=0$, and their utility increases linearly with the distance between the winning policy and the status quo. Their utility is $U_{c}^{B}=x_{c}-x_{q}$ if the counter proposal wins, and $U_{i}^{B}=x_{i}-x_{q}$ when the initiative wins. Petitioners pay campaigning costs $\kappa=\frac{k}{\bar{\mu}-\underline{\mu}}>0$ if they do not to withdraw the initiative. ${ }^{13}$ Campaigning in favor of the initiative is costly because it takes time, human and monetary resources. The expected campaigning costs amount to $E[k]=\bar{k}>0$ and are publicly known before the signature collection begins. The individual size of $k$ is disclosed only once the initiative is qualified. Figure 3 displays the extensive-form game tree, summarizing the following rules:

1. Nature chooses the initiative's winning probability.

2. Petitioners decide whether to enter the collection stage or not. If they do, they collect at least $\bar{s}$ signatures in time $t$.

3. Politicians decide whether to make a counter proposal at costs $c$, or not. They pay reputation costs $r$ if the status quo wins after a counter proposal.

\footnotetext{
${ }^{12}$ In a citizen-candidate setting, Osborne and Slivinski (1996) show the existence of three-candidate equilibria in which the middle candidate enters just to affect the voting result even though he himself has no chance to win.

${ }^{13}$ The functional form of campaigning $\operatorname{costs} \kappa$ is chosen for computational ease.
} 
4. Petitioners decide whether to withdraw the initiative or not. They pay campaigning costs $\kappa$ if they do not.

5. The winning policy according to sincere voting is announced.

6. Both players realize their payoffs. The winning policy is implemented.

\subsection{Discussion of Modeling Choices}

Uncertainty over the initiative's success probabilities is a key element of our model as it allows for distinct voting outcomes after the same equilibrium combination of voting alternatives. If, for example, the initiative is voted against the status quo, both options can win the vote with positive probability. Moreover, we explicitly model the initiative's success probability from information revealed by the signature collection process. The initiative's winning probability is a function of the status quo and initiative's positions on the real line, and the bounds of the median voter distribution. Since players need to know the positions of the status quo and the initiative to make decisions about counter proposals and initiative withdrawal, the link between signature collection and the initiative's winning probability is chosen to work through $\mu$.

In our model, both the status quo and the initiative are exogenous. We assume that petitioners act out of conviction and want to implement the policy they truly believe is best. In the sense of Kartik and McAfee (2007) they have character, and are unpolitical types (Calvert, 1985; Wittman, 1983). The initiative' position $x_{i}$ thus reflects the petitioners' preferred policy, maximizing their utility. Petitioners already derive utility from simply writing the initiative and drawing public attention towards their issue, very much in the sense of Habermas' (1992) discourse theory. Their bargaining power which gives them a positive expected payoff comes mainly from the possibility of withdrawing the initiative. Moreover, since players are uncertain about the initiative's winning probability, a nonstrategic positioning of the initiative is viable. An obvious extension of the model would be to allow petitioners choose the initiative point strategically. For example, Gerber (1996) develops a model in which proposing an initiative is costly, and therefore for a given status quo not all initiatives points are proposed.

In contrast to Gerber (1996) and Matsusaka and McCarty (2001), we do not assume that the status quo is set while anticipating the threat of a direct democratic initiative or referendum. We prefer to think of it as old regulation, or a topic that has not been regulated so far. It is commonly argued that office-motivated politicians implement policies preferred by the median voter. However, in models with more than two candidates the median voter's preferred policy is not necessarily implemented. Moreover, politicians are elected to implement a bundle of policies. Even if the elected politicians' bundle coincided with the median voter's preferences on average, this does not have to hold for every single policy in the bundle. Direct democracy, on the other hand, allows voters to see their preferences implemented for single issues (Kirchgässner \& Frey, 2012). 
There are two modeling choices associated with the counter proposal. First, in theory, politicians could design relatively far-reaching counter proposals that would not make the initiative withdraw. In this way, the counter proposal could serve to split the pro-reform votes to minimize the initiative's winning probability. This would considerably increase the status quo's winning probability. However, such counter proposals do not seem to be in line with the tradition of Swiss politics. Moreover, the parliament is legally required to make a positive voting recommendation in favor of the counter proposal on behalf of the electorate. This justifies the inclusion of reputation costs if the status quo wins after a counter proposal was made. ${ }^{14}$

Second, politicians decide whether to make a direct (constitutional) or indirect (statutory) counter proposal. Only the former has to be voted upon at the same time as the initiative while the latter can be implemented instantaneously. The decision whether to issue a direct or indirect counter proposal is mostly determined by considerations on the appropriate structure of law. Therefore, it is usually not a strategic decision which form to propose, so that we do not explicitly model this distinction between the two different kinds of counter proposals. ${ }^{15}$ In addition to issuing a counter proposal, politicians also have the option to support the initiative and issue a positive voting recommendation to the voters, which, however, happens very infrequently. While we do not include this as an alternative action of the politicians, it would be a straightforward extension of the model.

Regarding the signature collection process, we assume that politicians observe the state of signature collection at each point in time. Signatures are officially verified and counted only after they are filed with the Swiss Federal Chancellery, but very often the media report about the state of the ongoing signature collection before its close. ${ }^{16}$ Non-public information channels among politicians most likely lead to even better information about the state of signature collection among members of the political sphere.

\footnotetext{
${ }^{14}$ For example, in 1914 the Council of States wanted to issue a counter proposal against the initiative to introduce proportional representation, which was declined by the National Council since it seemed tactically motivated. Similarly, in 1953 the National Council opposed issuing a counter proposal because it was suspected to be proposed by some Members of Parliament for strategic reasons (Hofer, 2012).

${ }^{15}$ For example, the initiative for more salary benefits for parents was withdrawn in 2006 in favor of an indirect counter proposal which regulated the matter at the statutory level, since such a detailed regulation was not appropriate for a constitutional article. In contrast, the initiative on complementary medicine was withdrawn in favor of a direct (constitutional) counter proposal and voted on in 2009. The topic of complementary medicine and the possibility to include it into mandatory health insurance was a new subject to the constitution, so it was appropriate to have a constitutional article regulating the matter.

${ }^{16}$ E.g., it was widely published that the initiative to introduce inheritance taxes, started by an ad-hoc committee in 2011, was running behind schedule in signature collection (Schaffner, 2012). Similarly, it was well-known that the conservative-liberal party did not have many signatures for the initiative to reduce bureaucracy at an early stage of collection and finally did not qualify in 2012 (Mäder, 2010). In contrast, the Swiss Popular Party was extremely quick in collecting already more than half the required signatures for an initiative about the expulsion of criminal foreigners, which was broadly covered in the media (Fontana, 2012).
} 


\subsection{Subgame Perfect Equilibrium}

We solve the sequential model recursively beginning with the petitioners' best withdrawal strategy, then determine politician's best counter proposal strategy given their knowledge about how petitioners react to it. In a next step we derive petitioners' optimal signatures collection strategy given their knowledge about the politicians' equilibrium counter proposal strategy. We close with a brief description of the petitioners' entry into the initiative process problem.

\section{Petitioners' Optimal Withdrawal}

Petitioners either withdraw the initiative $(w=1)$ or not $(w=0)$. Their goal is to maximize the expected payoff over all potential voting outcomes. If a counter proposal is made, the maximization problem can be written as an optimal withdrawal rule:

$$
w^{*}\left(x_{c}\right)=\left\{\begin{aligned}
1 & \text { if } \pi_{q}\left(x_{q}, x_{c}\right) U_{q}^{B}+\pi_{c}\left(x_{q}, x_{c}\right) U_{c}^{B} \\
& \geq \pi_{q}\left(x_{q}, x_{c}, x_{i}\right) U_{q}^{B}+\pi_{c}\left(x_{q}, x_{c}, x_{i}\right) U_{c}^{B}+\pi_{i}\left(x_{q}, x_{c}, x_{i}\right) U_{i}^{B}-\kappa \\
0 & \text { else }
\end{aligned}\right.
$$

They optimally choose the option that yields the larger expected payoff: withdrawing the initiative such that the counter proposal competes only against the status quo, or not withdrawing such that the initiative competes against both the status quo and the counter proposal. In case of withdrawal, the counter proposal receives all votes that would otherwise have gone to the initiative, and thus the probability of reform increases. Also, campaigning costs do not accrue. At the same time petitioners forgo the chance that the initiative wins. Should both payoffs be equal, we assume that the initiative is withdrawn. The optimal withdrawal rule can be written as a cutoff function of the counter proposal as shown in the appendix.

Proposition 1 (Equilibrium Petitioners) There exists a cutoff $\bar{x}_{c}$ such that the initiative is withdrawn for counter proposals greater or equal to the cutoff, and not withdrawn else:

$$
w^{*}\left(x_{c}\right)= \begin{cases}1 & \text { if } x_{c} \geq \bar{x}_{c} \\ 0 & \text { if } x_{c}<\bar{x}_{c}\end{cases}
$$

Intuitively, petitioners withdraw the initiative if the counter proposal is a satisfactory compromise. Otherwise they prefer to try their chances at ballot.

Proposition 1 (Equilibrium Petitioners) states that if politicians do not make a counter proposal, petitioners optimally withdraw the initiative if the campaigning costs exceed the expected payoff difference from having the initiative voted against the status quo and no ballot. If the initiative is withdrawn without counter proposal, the status quo wins unchallenged. The expected payoff from not withdrawing the initiative is $\pi_{q}\left(x_{q}, x_{i}\right) U_{q}^{B}+\pi_{i}\left(x_{q}, x_{i}\right) U_{i}^{B}-\kappa$. It follows that petitioners prefer to withdraw the initiative if $\pi_{i}\left(x_{q}, x_{i}\right)\left(U_{i}^{B}-U_{q}^{B}\right)<\kappa$, i.e., if campaigning costs are relatively large 
Numerical Example Cutoff Counter Proposal: Figure 4 displays the cutoff counter proposal for the numerical example $b=0.24$ (winning interval of counter proposal without withdrawal), and $k=0.1$ (campaigning costs). We get $\bar{x}_{c} \approx 0.53$ such that petitioners optimally withdraw the initiative for all $x_{c} \in[0.53,0.85)$ as represented by the dashed line but not below.

Fig. 4: Example of Cutoff Counter Proposal

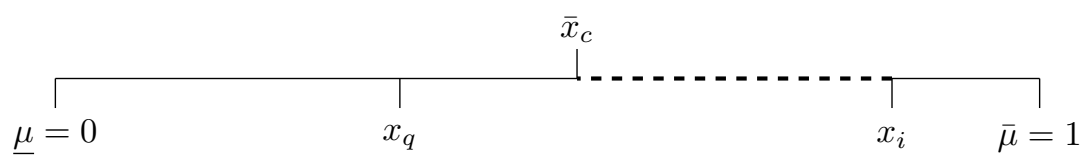

Note: Median distribution $\mu \sim U[0,1]$, status quo $x_{q}=0.35$, initiative $x_{i}=0.85$, counter proposal winning interval $b=0.24$, and campaigning costs $k=0.1$. The cutoff is at $\bar{x}_{c} \approx 0.53$, such that the initiative is withdrawn when the counter proposal is located on the dashed line.

compared to expected payoffs.

\section{Politicians}

Politicians either make a counter proposal $x_{c}$, or refrain from compromising, $x_{c}=\varnothing$. In the subgame perfect equilibrium politicians take into account that petitioners withdraw the initiative if the counter proposal is at or above the cutoff $\bar{x}_{c}$.

The politicians' expected payoff maximization is a two-stage problem. First, they consider which point $x_{c} \in\left(x_{q}, x_{i}\right)$ to propose optimally if they were obliged to make a counter proposal. Second, they decide whether to make this optimal counter proposal, or make none at all.

The first-stage problem is a choice between a vote of the status quo against a counter proposal at or above the cutoff $\bar{x}_{c}$, and a vote with all three alternatives competing against each other.

$$
x_{c}^{*}=\left\{\begin{aligned}
x_{c} \geq \bar{x}_{c} & \text { if } \pi_{q}\left(x_{q}, x_{c}\right)\left(U_{q}^{A}-r\right)+\pi_{c}\left(x_{q}, x_{c}\right) U_{c}^{A}-c \\
& \geq \pi_{q}\left(x_{q}, x_{c}, x_{i}\right)\left(U_{q}^{A}-r\right)+\pi_{c}\left(x_{q}, x_{c}, x_{i}\right) U_{c}^{A}+\pi_{i}\left(x_{q}, x_{c}, x_{i}\right) U_{i}^{A}-c \\
x_{c}<\bar{x}_{c} & \text { else }
\end{aligned}\right.
$$

In the appendix we show that a cutoff $\bar{r}$ of reputation costs characterizes the politicians' best strategy:

Proposition 2 (Counter Proposal Politicians) ${ }^{17}$ If politicians were obliged to make a counter proposal, they would optimally choose

$$
x_{c}^{*}(r)= \begin{cases}\bar{x}_{c} & \text { if } r \leq \bar{r} \\ x_{q}+\epsilon, \epsilon \rightarrow 0 & \text { if } r>\bar{r}\end{cases}
$$

\footnotetext{
${ }^{17}$ This holds if the status quo wins more likely with $x_{c}=\bar{x}_{c}$ than with $x_{c}=x_{c}^{\prime \prime}$. Otherwise the condition is reversed and $x_{c}^{*}(r)=\bar{x}_{c}$ if $r>\bar{r}$ and $x_{q}+\epsilon, \epsilon \rightarrow 0$ else.
} 
Numerical Examples Median Distribution Cutoff: Keeping all other values constant, we assume that the costs of making a counter proposal are $c=0.04$, and the reputation costs are $r=0.2$. Then $r<\bar{r} \approx 1.3$ and politicians decide between $x_{c}^{*}=\bar{x}_{c}$ and $x_{c}^{*}=\varnothing$ in equilibrium (upper panel). We get that $\mu^{c}=0.14$. When the belief about the lower bound is $\mu \in[0,0.14)$, represented by the thick solid line, the initiative's winning probability against the status quo is low enough that it is not considered a threat to the status quo, and politicians optimally make no counter proposal. Whenever $\mu \in[0.14,0.35]$, which is the dashed part of the line, the initiative has a high enough winning probability to provoke a counter proposal at the cutoff $\bar{x}_{c}$. Specifically, if the initiative's winning probability is greater of equal $\pi\left(x_{q}, x_{i}\right)=0.44$, politicians make a counter proposal and else not. With reputation costs of $r=1.4$ we have $r>\bar{r} \approx 1.3$ and politicians decide between $x_{c}^{*}=x_{q}+\epsilon$ and $x_{c}^{*}=\varnothing$ in equilibrium (lower panel).

Fig. 5: Examples of Initiative Type and Winning Probability

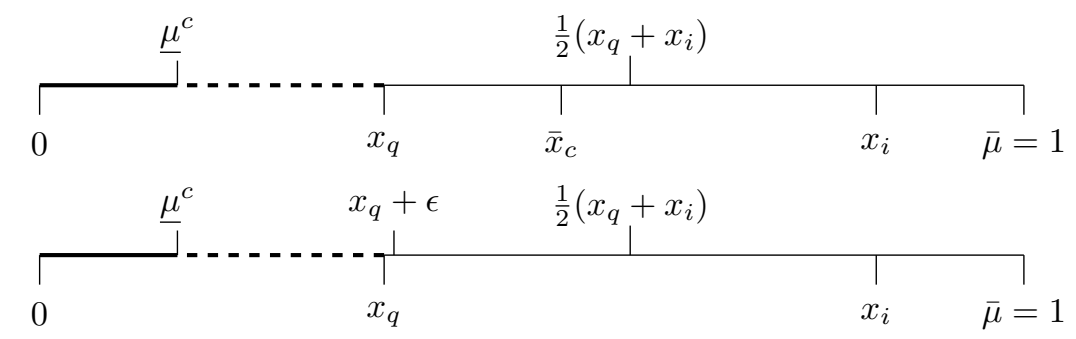

Note: Median distribution upper bound $\bar{\mu}=1$, status quo $x_{q}=0.35$, initiative $x_{i}=0.85$, counter proposal winning probability $b=0.24$, campaigning costs $k=0.1$, cutoff for withdrawal at $\bar{x}_{c}=0.53$, costs of making counter proposals $c=0.04$, politicians' reputation costs $r=0.2$. The initiative gets no counter proposal for beliefs $\underline{\mu} \in[0,0.14)($ thick line), and a cutoff counter proposal for $\underline{\mu} \in[0.14,0.35]$ (dashed line). Parameter values in the lower panel are identical to those in the upper panel with the exception of politicians' reputation costs which are set to $r=1.4$.

Depending on the reputation costs, politicians either prefer a small compromise $x_{c}^{\prime \prime}=x_{q}+$ $\epsilon, \epsilon \rightarrow 0$ close to the status quo after which the initiative is not withdrawn. We call this a minor counter proposal. Or they prefer the cutoff counter proposal $\bar{x}_{c}$ after which petitioners withdraw the initiative. We assume that politicians propose the cutoff when the equation holds with equality. ${ }^{18}$

Politicians' second-stage optimization problem requires the decision whether to make a counter proposal as laid out in Proposition 2 (Counter Proposal Politicians) and pay costs $c$, or not to compromise and have a vote between initiative and status quo. The tradeoff politicians face is that by not making a counter proposal they might get a high utility from the status quo, but also risk very low utility in case the initiative wins. In contrast, a counter proposal gives positive winning probability to a policy option with medium-sized utility and a cost $c$.

The equilibrium strategy depends on cutoffs of the belief regarding the initiative's winning probability. Recall that the latter is represented by the lower bound of the median distribution $\underline{\mu} \in\left[0, x_{q}\right]$. Above the cutoff the initiative is too likely to win and compromising is the better

\footnotetext{
${ }^{18}$ In our model only the narrow counter proposal $x_{c}^{\prime \prime}=x_{q}+\epsilon, \epsilon \rightarrow 0$ that does not make petitioners withdraw the initiative. This does not mean that all counter proposals without withdrawal are minor political concessions. To be considered a real alternative to the status quo counter proposals have to offer substantial compromise. The model could be easily adapted by requiring a minimal distance $\delta$ between $x_{q}$ and $x_{c}$. Politicians would then optimally choose $x_{c}^{*}=x_{q}+\delta$ if the expected payoff from doing so was larger than from proposing $x_{c}^{*}=\bar{x}_{c}$. While adding this feature to the model would make it more realistic, it would not be distinguishable from the simpler specification.
} 
option, and vice versa below the cutoff (proof in appendix). If beliefs are at the cutoff, we assume that politicians make a counter proposal.

Proposition 3 (Equilibrium Politicians) If $r \leq \bar{r}(r>\bar{r})$, there exists a median distribution cutoff $\underline{\mu}^{c}\left(\underline{\mu}^{c^{\prime}}\right)$ below which no counter proposal is made, and above which a counter proposal is optimally made:

$$
x_{c}^{*}(r, \underline{\mu})= \begin{cases}\bar{x}_{c} & \text { if } r \leq \bar{r} \wedge \underline{\mu} \geq \underline{\mu}^{c} \\ x_{q}+\epsilon, \epsilon \rightarrow 0 & \text { if } r>\bar{r} \wedge \underline{\mu} \geq \underline{\mu}^{c^{\prime}} \\ \varnothing & \text { else }\end{cases}
$$

It follows that if the cutoff lies in the domain of $\underline{\mu} \in\left[0, x_{q}\right]$ and the initiative wins with sufficiently high probability, politicians make a counter proposal. ${ }^{19}$

\section{Optimal Signature Collection}

Petitioners continuously choose whether to collect signatures, or to stop. They have two goals: first, they want to qualify the initiative for ballot; it is thus never optimal to stop collection before the legal threshold $\bar{s}$ is reached. Second, they know that collection reveals information about the initiative's winning probability and affects the politicians' optimal strategy. The longer they collect, the more certain are the players about the winning probability.

The outcome of the signature collection has no impact on the counter proposal if the cutoffs $\underline{\mu}^{c}$ and $\underline{\mu}^{c^{\prime}}$ are outside the domain of $\underline{\mu} \in\left[0, x_{q}\right]$ because in this case politicians' optimal strategy is independent of $\mu$, and petitioners optimally stop collecting at the qualifying threshold. In what follows, we focus on the case in which the politician's strategy depends on the value of $\underline{\mu}$.

If reputation costs are high, $r>\bar{r}$, politicians either make the minor counter proposal or none. Petitioners are indifferent between the two outcomes (cf. appendix for the proof), and therefore they have no incentive to collect more than the signature requirement. If $r \leq \bar{r}$ politicians either propose the cutoff counter proposal or none, and petitioners always prefer the former to the latter (cf. appendix for the proof). They take into account that politicians' only make the counter proposal if the belief about the initiative's winning probability is relatively high.

Consider Figure 7 with time on the x-axis and belief $\underline{\mu}_{t}$ on the y-axis: if the petitioners collect $\bar{s}$ signatures and beliefs are above $\underline{\mu}^{c}$, they receive the cutoff counter proposal. It follows that petitioners optimally do not over-collect if either initial belief $\underline{\mu}_{0}$ is sufficiently high, or they receive a lump sum and are a high type with certainty.

The more interesting case occurs if beliefs fall below $\underline{\mu}^{c}$ once the signature requirement is reached and no lump sum has been observed. If petitioners stop collecting, they get no counter proposal, and no further collection costs accrue. Alternatively, they continue at costs $\gamma$, and get a cutoff counter proposal with the probability of observing a high lump sum $\lambda p_{t}$ (the product of the probability of being a high type and the lump sum $s_{h}$ arriving). Denote the belief for which petitioners are

\footnotetext{
${ }^{19}$ Note that the cutoff potentially lies outside the domain of $\underline{\mu}$, and politicians' best strategy is independent of $\underline{\mu}$ then.
} 
Fig. 6: Politicians' Best Strategy

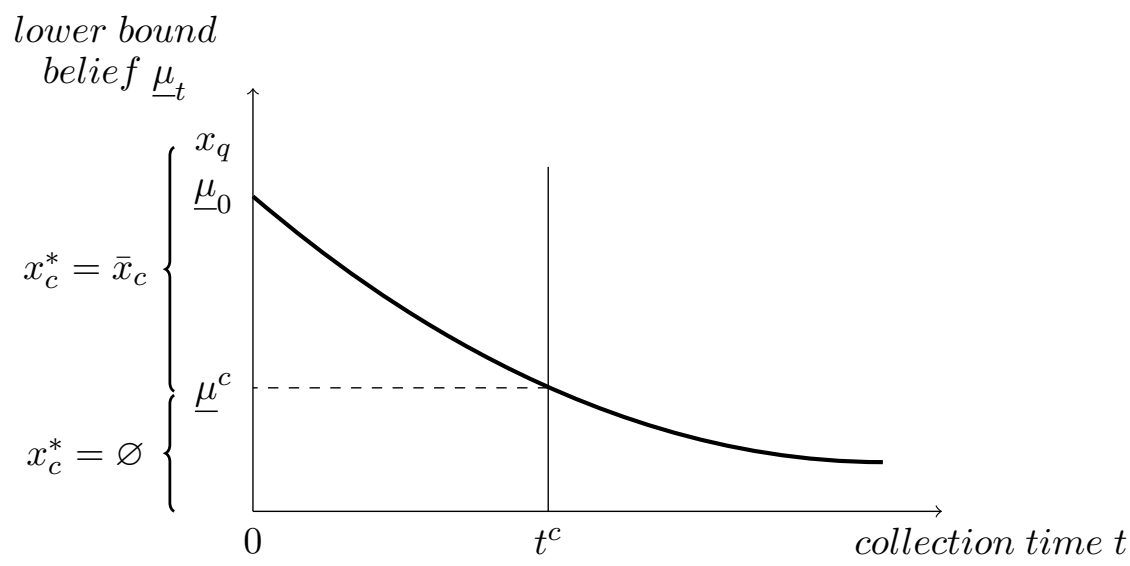

Note: The vertical axis displays petitioners' belief about the median distribution's lower bound, the horizontal axis represents time. The figure shows the best action played by politicians depending on collection time. If no lump sum occurs and collection stops above $\underline{\mu}^{c}$, politicians make a counter proposal. If not lump sum occurs and collection stops below $\underline{\mu}^{c}$, they make none.

indifferent between these options by $\underline{\underline{\mu}}$. For all beliefs above this threshold, beliefs to be a high type are high enough such that continuing collection is more beneficial than stopping, and vice versa. When beliefs equal the threshold, we assume that collection is preferred.

Proposition 4 (Optimal Collection) Petitioners optimally continue collection until they qualify the initiative. If reputation costs are small, $r \leq \bar{r}$, the probability cutoff is in the relevant domain $\left(\underline{\mu}^{c} \in\left[0, x_{q}\right]\right)$ and beliefs are sufficiently high $\left(\underline{\mu}_{t} \geq \underline{\hat{\mu}}\right)$, petitioners optimally over-collect.

In sum, petitioners over-collect only if they believe to be high types with sufficiently high probability even though no lump sum has occurred.

\section{Entry Decision}

As a final step, we briefly discuss petitioners' decision to enter the qualification stage. If politicians' reputation costs are high, $r>\bar{r}$, petitioners have the same expected payoff irrespective of the signature collection, and expect type-weighted costs for collecting the signature requirement. ${ }^{20}$

If reputation costs are low, $r \leq \bar{r}$, petitioners get a type- and lump sum probability-weighted payoff of receiving the cutoff counter proposal or none. Expected collection costs take into account the probability of over-collection.

\footnotetext{
${ }^{20}$ In more detail, $E[\Gamma]=p_{0} \int_{0}^{\bar{s} /\left(s_{l}+\lambda s_{h}\right)} \gamma d t+\left(1-p_{0}\right) \int_{0}^{\bar{s} / s_{l}} \gamma d t$ where $\left(s_{l}+\lambda s_{h}\right)$ and $s_{l}$ are the expected number of signatures per period for high and low types respectively, and $\bar{s} /\left(s_{l}+\lambda s_{h}\right)$ and $\bar{s} / s_{l}$ is the expected time to collect $\bar{s}$ signatures. Integrating over time yields $E[\Gamma]=\gamma \bar{s}\left[p_{0} /\left(s_{l}+\lambda s_{h}\right)+\left(1-p_{0}\right) / s_{l}\right]$.
} 
The expected payoff net of expected signature collection costs must be positive for petitioners to start signature collection.

\subsection{Hypotheses}

Proposing an initiative amends the status quo either by directly defeating it at the vote, or provoking a successful counter proposal. The probability of reform $\operatorname{Pr}\left(x_{q}\right.$ amended $)=1-\operatorname{Pr}\left(x_{q}\right.$ wins $)$ depends on the status quo's winning probability:

$$
\begin{aligned}
\pi_{q}\left(x_{q}, x_{i}\right) & =\frac{\frac{1}{2}\left(x_{q}+x_{i}\right)-\underline{\mu}}{\bar{\mu}-\underline{\mu}} \\
\pi_{q}\left(x_{q}, \bar{x}_{c}\right) & =\frac{\frac{1}{2}\left(x_{q}+\bar{x}_{c}\right)-\underline{\mu}}{\bar{\mu}-\underline{\mu}} \\
\pi_{q}\left(x_{q}, x_{c}, x_{i}\right) & =\frac{\frac{1}{2}\left(x_{c}+x_{i}\right)-\underline{\mu}-b}{\bar{\mu}-\underline{\mu}}
\end{aligned}
$$

The cutoff counter proposal inherits all votes from the initiative when the latter is withdrawn. Moreover, it is closer to the status quo than the initiative, and thus appeals to even more voters. Obviously, the status quo is less likely to win in a direct vote against the cutoff counter proposal than against the initiative, $(2)-(1)>0$. Comparing (1) to (3) shows that the status quo is more likely amended if the minor counter proposal was issued. ${ }^{21}$ The compromise takes away votes from the status quo, and either a successful counter proposal or the initiative can bring about reform.

Our model shows that signature collection is an important information source when politicians decide whether to issue a counter proposal. By Proposition 4, only initiatives considered a threat to the status quo receive a counter proposal: either they have a high initial belief about the winning probability, or a lump sum of signatures is observed. Initiatives with lump sums are faster collectors in expected term. As a consequence, initiatives with counter proposals collect at least as quickly as initiatives without counter proposals. ${ }^{22}$ Conversely, initiatives with lump sums are fast collectors and are thus more likely to receive a counter proposal than slow collectors. The probability of reform is higher for initiatives with counter proposals. Our main hypothesis is thus:

Hypothesis 1 (Signatures and Reform) Fast collectors are more likely to induce reform than slow collectors Initiatives collecting quickly are more likely to induce reform than slow collectors.

The next testable implication relates to the link between signature collection and the probability of receiving a counter proposal.

Hypothesis 2 (Counter Proposals) On average, initiatives with counter proposals collect signatures at least as quickly as initiatives without counter proposals. Initiatives that over-collect and

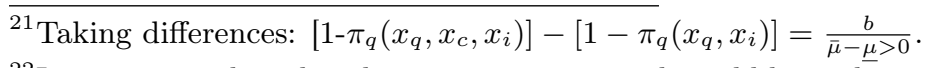

${ }^{22}$ Initiatives with and without counter proposal would have the same average collection rate if all initiatives had high initial beliefs such that all initiatives received counter proposals without observing a lump sum.
} 
Fig. 7: Overview Hypotheses

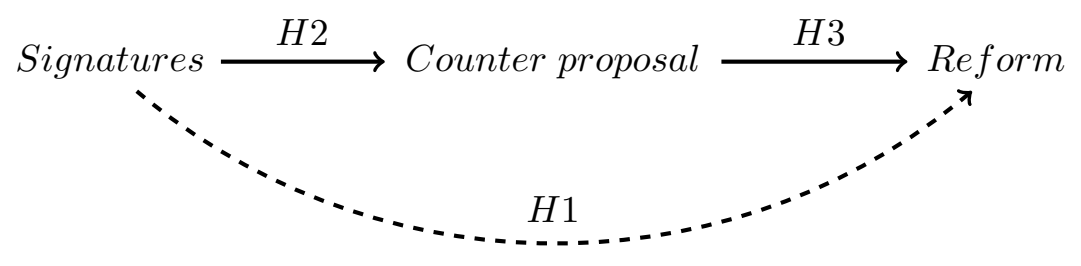

Fig. 8: The number of signatures and collection time affect the probability of counter proposals (H2) which in turn affect the probability of reform (H3). The overarching effect leads from signatures to the probability of reform (H1).

later receive a cutoff counter proposal, are strictly faster collectors than initiatives without counter proposal.

The model yields the following hypothesis regarding the link between counter proposals and the probability of reform:

Hypothesis 3 (Status Quo) After a counter proposal the status quo is more likely to be amended than when the initiative is voted exclusively against the status quo.

The three hypotheses and their relation are summarized in Figure 8. The first hypothesis relates signatures and the probability of reform. This effect is disaggregated into the other two hypotheses with counter proposals linking signatures and reform.

\section{Data and Empirical Strategy}

\subsection{Data}

We collected a dataset of all 249 qualified Swiss federal initiatives. It covers the entire time span from the introduction of the initiative in 1891 to $2010 .^{23}$

We have information on the counter proposal, withdrawal, and the voting outcomes. ${ }^{24}$ Let $\sigma_{p o l} \in\{C P, n C P\}$ denote the politicians' decision about the counter proposal where $C P$ stands

\footnotetext{
${ }^{23}$ We omit four initiatives that had been declared invalid by the parliament and were not further discussed thereon. We also drop two initiatives that collected the necessary number of signatures, but were postponed by the government and parliament for exceptionally long periods of time until they became irrelevant and were written off by parliament (cf. Swiss Federal Chancellery, 2013). Furthermore, we omit three initiatives that were withdrawn after a counter proposal to a similar, but different initiative had been made. The three cases are the initiative "Special justice in cases of urgency (Notrecht und Dringlichkeit)" (withdrawn 1940) and two initiatives on old age insurance "Initiative for an entirely public-based pension scheme" ("Für die Einführung einer Volkspension") (withdrawn in 1974) and "Further expansion of insurances against old age and invalidity" ("Für einen weiteren Ausbau der Alters-, Hinterlassenen- und Invalidenversicherung") (withdrawn in 1968). For these initiatives the reaction of both the parliament and the petitioners cannot be clearly allocated to one initiative, but was mainly driven by other contemporaneous initiatives on similar subjects (Hofer, 2012).

${ }^{24}$ As explained, indirect counter proposals may be subject to a facultative referendum but this rarely occurs. However, in the few cases in which this happened, we take into account the outcome of the referendum vote.
} 
for a counter proposal and $n C P$ indicates that none has been made. Analogously, $\sigma_{p e t} \in\{w, n w\}$ reflects whether petitioners withdrew the initiative $(w)$ or not $(n w)$. Combined, we have four mutually exclusive observed profiles of politicians' and petitioners' choices: $\sigma=\left(\sigma_{\text {pol }}, \sigma_{\text {pet }}\right) \in$ $\{(C P n w),(C P w),(n C P n w),(n C P w)\}$. The profile frequencies are 27, 54, 145, and 23 respectively. We also recorded the timing of the initiative's political process to allocate them correctly into institutional periods. ${ }^{25}$

According to the Swiss Federal Chancellery, 23 initiatives without a counter proposal were withdrawn for "other reasons" (as opposed to withdrawal after a counter proposal). We collected complementary data on the initiative from the detailed descriptions of each initiative in Hofer (2012) and Rohner (2012). They provide additional insight into smaller policy concessions by the parliament which were not explicitly registered as counter proposals, but still represent some policy change induced by the initiative. We recoded 10 of the 23 initiatives of profile $(n C P w)$ that yielded minor policy changes according to Rohner (2012) and Hofer (2012) as having a de facto counter proposal and thus profile $(C P w)$. We run our estimates with the officially coded data, but repeat all estimates including the de facto counter proposals.

In Switzerland all signatures are subject to verification in contrast to random sampling procedures common in many US states. We assembled the number of collected, valid and invalid signatures. As it is of particular importance for the model, let Over-collection $=$ Signatures $-\bar{s}$ denote the number of valid signatures collected above the legal threshold $\bar{s}$. Time is the signature collection time measured from collection begin to submitting the signatures. ${ }^{26}$ The variable Speed is defined as $\frac{\text { Signatures } / 100}{\text { Days }}$, and reflects the number of signatures in hundreds collected per day. On average, initiatives are qualified with around 38.500 signatures more than legally required within 363 days. This corresponds to 480 signatures per day collected on average.

We collected data on control variables regarding the petitioners' and initiative's characteristics potentially influencing the initiative process. Initiatives are usually proposed by either parties, associations, groups of private organizations or individuals. We control for the variable Party $=1$. $30.1 \%$ of petitioners are parties.

Petitioners can be distinguished depending on their experience in raising initiatives: Experienced $=1$ denotes a committee that already raised at least one initiative before, and inexperienced if it raises an initiative for the first time. For example, when the Social Democrats qualified their first initiative in 1893, they are coded as Experienced $=0$. For its next initiative in 1899, they had already gained experience in the initiative process, and are thus coded as Experienced $=1$. In total, $46.6 \%$ of the committees are experienced. The number indicates that many committees raise initiatives repeatedly.

As a third control variable we attribute an economic, ideological or state-related topic to each initiative according to initiative titles, its precise wording (2013), and contextual information (Hofer

\footnotetext{
${ }^{25}$ The precise description of the rules to allocate the initiatives to the six institutional periods can be found in the appendix.

${ }^{26}$ For four initiatives collection time is not available. As all four belong to periods before the collection time restriction, we assume the mean collection time before 1978 for them.
} 
Table 1: Descriptives

\begin{tabular}{lcccc}
\hline & Mean & Std. Dev. & Min & Max \\
\hline Over-collection & 38.496 & 51.220 & 0.038 & 334.760 \\
Time & 362.9 & 188.8 & 34 & 1173 \\
Speed & 4.759 & 5.463 & 0.515 & 55.443 \\
Party & 0.301 & 0.560 & 0 & 1 \\
Experienced & 0.466 & 0.500 & 0 & 1 \\
Economic & 0.430 & 0.496 & 0 & 1 \\
De Facto & 0.040 & 0.197 & 0 & 1 \\
\hline
\end{tabular}

Note: Summary statistics for the complete sample. Over-collection is defined as valid signatures legal threshold in thousands. Time is measured in days from collection begin to submitting the signatures. Speed is the number of signatures (in hundreds) collected per day. Dummy Party is one for parties. Dummy experienced is one if the initiating committee has raised at least one initiative before. If a topic is economically framed (and not ideologically or staterelated), the dummy Economic is 1. Defacto takes value 1 if an initiative received a de facto counter proposal.

(2012)). ${ }^{27}$ The dummy Economic takes value 1 if the topic is economic, and value 0 otherwise. $42.97 \%$ of the initiatives deal with an economic topics. The remaining ones are split among ideological (48.59\%) and state-related topics (8.43\%).

Table 1 provides descriptive statistics, a detailed overview of the data sources can be found in Table 8 in the appendix.

\subsection{Empirical Strategy}

To test model predictions and estimate its quantitative importance, we link the equilibrium strategies to their empirical counterparts. Our model predicts that the initiative is withdrawn after counter proposals at the cutoff: from observing profile $(C P w)$, it follows that the cutoff counter proposal is made. Similarly, observing profile (CPnw) means that a minor counter proposal is made after which the initiative is not withdrawn. Profiles $(n C P w)$ and $(n C P n w)$ reflect the cases when no counter proposal is issued and petitioners either do or do not withdraw the initiative.

The first relationship to be explored is the impact of the signature collection rate on the prob-

\footnotetext{
${ }^{27}$ For example, the initiative for a tax on capital gains (voted in 2001) is a good example for an initiative that focuses primarily on monetary redistribution of economic assets. On the other hand, the initiative "for mother and child - protection of the unborn child and help to the mother in need" against abortion (voted in 2002) was raised for non-economic, cultural or ideological reasons. A similar example is the initiatives raised against nuclear power plants, such as the initiative "electricity without nuclear energy" (voted in 2003). Finally, initiatives on state-related topics include the initiatives to switch from majoritarian to proportional representation (for example, "proportional election of the National Council" voted in 1918) or the proposal to allow popular referendums in the case of international treaties (voted in 1977).
} 
ability of amending the status quo, Hypothesis 1 (Signatures and Reform): initiatives with short collection times should be more associated with a higher likelihood to reform the status quo. Initiatives are indexed by $i$, and $p$ denotes their institutional period. The binary dependent variable Amended $_{i p}$ is 1 if the status quo is amended (either initiative or counter proposal wins), and 0 else. The main independent variables is the signature collection rate defined as signatures in hundreds collected per day, Rate $=\frac{\text { Signatures } / 100}{\text { Days }}$. Vector $z_{i p}$ controls for initiative-specific variables as explained in the data section. Institutional period fixed effects $\xi_{p}$ account for period-specific changes in the regulation regarding the initiative process. We thus estimate within-period variations, and not the effect of institutional changes on the probability of reform. We drop initiatives of the profile $(n C P w)$ (withdrawn without counter proposal) as this profile is a perfect predictor for initiative failure. Versions of the following regression equation are estimated:

$$
\operatorname{Prob}\left(\text { Amended }_{i p}=1\right)=\Phi\left(\alpha+\beta_{1} \text { Rate }_{i p}+\zeta z_{i p}+\xi_{p}+\epsilon_{i p}\right)
$$

Coefficient $\beta_{1}$ reflects the impact of the signature collection rate on the probability of amending the status quo. $\alpha$ is the intercept and $\zeta$ is the vector of coefficients of initiative controls. Since the dependent variable is a dummy variable, a probit estimator is the most appropriate estimation method. Then $\epsilon_{i p}$ is a normally distributed error term with zero mean.

Hypothesis 2 (Counter Proposal) claims that initiatives with counter proposals should on average be at least as fast collectors as initiatives without counter proposals. Initiatives that over-collect and provoke a cutoff counter proposal, $(C P w)$, should be strictly faster collectors than the former because they receive additional lump sums of signatures. The dependent variable $C P_{i p}=1$ if any kind of counter proposal was made, and zero else. We run separate regressions dropping all initiatives with minor counter proposals. In this case the dependent variable is one if a cutoff counter proposals was issued. To test the hypothesis we run regressions of the following form:

$$
\operatorname{Prob}\left(C P_{i p}=1\right)=\Phi\left(\alpha+\beta_{2} \text { Rate }_{i p}+\zeta z_{i p}+\xi_{p}+\epsilon_{i p}\right)
$$

We expect $\beta_{2}$ to be nonnegative in regressions encompassing all initiatives, and strictly positive after dropping initiatives with minor counter proposals.

In the last part we estimate the relation between counter proposals and their effect on the probability of reform. By Hypothesis 3 (Status Quo) we expect it to be positive. We estimate the following equation:

$$
\operatorname{Prob}\left(\text { Amended }_{i p}=1\right)=\Phi\left(\alpha+\beta_{3} C P_{i p}+\zeta z_{i p}+\xi_{p}+\epsilon_{i p}\right)
$$

In alternative specifications, we disaggregate counter proposal into two dummies for the profiles $(C P w)$ and $(C P n w)$ respectively to explore heterogeneous effects. Hypothesis 3 postulates that coefficient $\beta_{3}$ should be positive. 


\section{Results}

Since all dependent variables are bivariate, we run probit regressions with robust standard errors. In the results tables we report marginal effects. Standard errors are calculated acknowledging that observations may not be independent from each other.

With a data set spreading over almost 120 years, time effects potentially play some role. Institutional period fixed effects account for the main institutional changes. Moreover, technology improvements and development of the media affect the initiative and signature collection process over time (Matsusaka, 1992). Political developments are also likely to influence the initiative process. For robustness, we thus include linear and quadratic time trends one at a time.

As alternative specification, we also run regressions including de facto counter proposals accounting for small changes in legislation induced by initiatives (cf. Section 4.1). Coefficients retain the same significance levels.

\subsection{Signatures and the Probability of Reform}

The model predicts that fast signature collectors should have a higher probability of amending the status quo than slow collectors (Hypothesis 1 Signatures and Reform). We run specifications for the complete sample but also split the sample around 1978, when collection time was restricted

and signature requirements doubled. The results are in Table 2. The estimated effect is positive throughout various regressions, however, the coefficients are only significant in the pre-1978 period. 100 more signatures per day, translating to 36,500 per year, increases the probability of changing the status quo by 1.5 to 2.4 percentage points.

After restricting the qualification criteria to 100.000 signatures and 18 months collection time the significant relation between the signature collection rate and the probability of reform disappears. To get more insight about the potential causes, we plot over-collection (i.e., valid signatures net the signature requirement) in thousands against collection time in days in Figure 9. The left panels are initiatives which changed the status quo, whereas the right ones did not. The upper (lower) panels are before (after) 1978.

Comparing successful and unsuccessful initiatives in the pre-1978 period demonstrates that initiatives amending the status quo collect a large number of signatures within few days. Consequently, they are fast collectors. This contrasts with unsuccessful initiatives which are scattered around the signature requirement and need more collection time. 
Fig. 9: Signatures and Collection Time by Reform
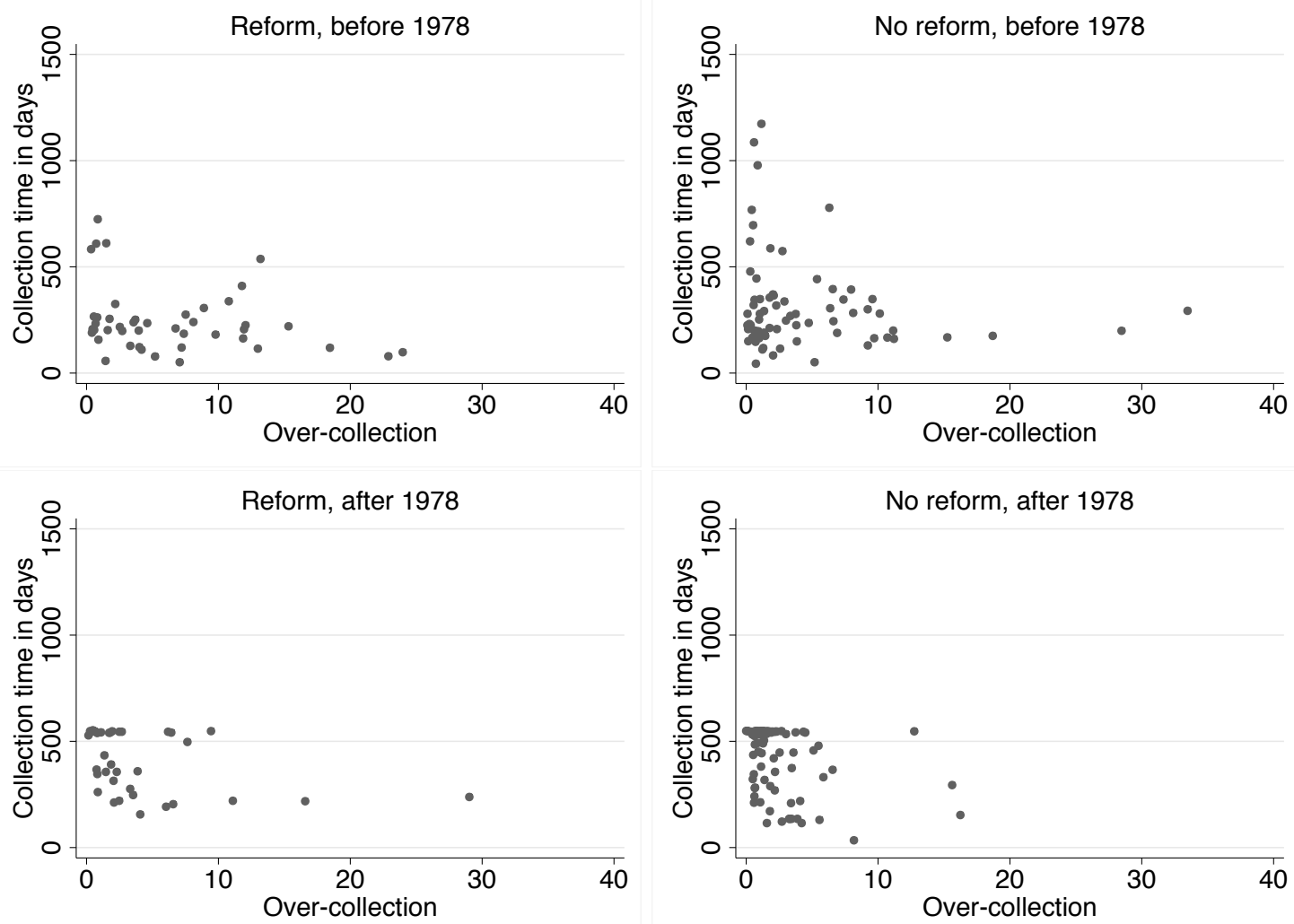

Note: Over-collection is defined as valid signatures - legal threshold in thousands. Collection time is measured in days. Before 1978 the signature requirement was 50.000 signatures. Afterwards it was 100.000 and collection time was restricted to 18 months (around 548 days). 
Table 2: Effect of Collection Rate on Probability of Reform

\begin{tabular}{|c|c|c|c|c|c|c|c|c|c|c|c|c|}
\hline Sample & $\begin{array}{l}(1) \\
\text { (all) }\end{array}$ & $\begin{array}{c}(2) \\
\text { (all) }\end{array}$ & $\begin{array}{c}(3) \\
\text { (all) } \\
\end{array}$ & $\begin{array}{l}(4) \\
\text { (all) }\end{array}$ & $\begin{array}{c}(5) \\
(<78) \\
\end{array}$ & $\begin{array}{c}(6) \\
(<78) \\
\end{array}$ & $\begin{array}{c}(7) \\
(<78) \\
\end{array}$ & $\begin{array}{c}(8) \\
(<78) \\
\end{array}$ & $\begin{array}{c}(9) \\
(>77) \\
\end{array}$ & $\begin{array}{c}(10) \\
(>' 77)\end{array}$ & $\begin{array}{c}(11) \\
(>>77) \\
\end{array}$ & $\begin{array}{c}(12) \\
\left(>^{\prime} 77\right)\end{array}$ \\
\hline Rate & $\begin{array}{l}0.012^{*} \\
(0.007)\end{array}$ & $\begin{array}{c}0.009 \\
(0.006)\end{array}$ & $\begin{array}{l}0.013^{*} \\
(0.007)\end{array}$ & $\begin{array}{c}0.010 \\
(0.006)\end{array}$ & $\begin{array}{c}0.021^{* * *} \\
(0.008)\end{array}$ & $\begin{array}{c}0.015^{* *} \\
(0.008)\end{array}$ & $\begin{array}{c}0.024^{* * *} \\
(0.007)\end{array}$ & $\begin{array}{c}0.021^{* * *} \\
(0.007)\end{array}$ & $\begin{array}{c}0.004 \\
(0.007)\end{array}$ & $\begin{array}{c}0.005 \\
(0.007)\end{array}$ & $\begin{array}{c}0.002 \\
(0.007)\end{array}$ & $\begin{array}{c}0.003 \\
(0.007)\end{array}$ \\
\hline Observations & 226 & 226 & 226 & 226 & 106 & 106 & 106 & 106 & 120 & 120 & 120 & 120 \\
\hline Period FE & no & yes & no & yes & no & yes & no & yes & no & yes & no & yes \\
\hline Controls & no & no & yes & yes & no & no & yes & yes & no & no & yes & yes \\
\hline
\end{tabular}

Note: ${ }^{* * *} \mathrm{p}<0.01,{ }^{* *} \mathrm{p}<0.05,{ }^{*} \mathrm{p}<0.1$. Probit regressions, marginal effects reported. Robust standard errors in brackets. Dependent variable: dummy is 1 if status quo was amended. Observations with profile $(n C P w)$ are dropped because they predict initiative failure perfectly. Rate is defined as $\frac{\text { Signatures } / 100}{\text { Days }}$. Controls: Party $=1$ for initiatives proposed by parties. Experienced petitioners petitioners are Experienced $=1$. Economic $=1$ for economically framed initiatives. Period fixed effects are based on 6 institutional periods. Columns (1)-(4) are based on the complete sample, (5)-(8) on initiatives voted before 1978, and (9)-(12) afterwards. 
After the 1978 policy change there is less over-collection and collection time is concentrated close to the maximum time of 18 months (approximately 548 days). There is little visible difference between successful and unsuccessful initiatives.

In sum, we find the expected relation between the signature collection rate and the probability of reform in the institutional setting prior to 1978. This setting corresponds to the model assumptions. With a collection time restriction, the informative mechanism from common learning through the signature collecting process breaks down. The possibility to over-collect in order to show high potential of reform is much more limited.

\subsection{Signature Collection}

In a second step we disaggregate the main effect running from signatures to reform into two subresults. Hypothesis 2 (Collection Speed) predicts a non-negative (positive) relation between the signature rate and the probability of counter proposal (cutoff counter proposal). Results are reported in Tables 3 and 4 . We run regressions with all counter proposals as dependent variable, specifications (1)-(4), and cutoff counter proposals, (5)-(8), as well as minor counter proposals, (9)-(12), separately. We also split the sample by the year 1978 as we expect differential effects similar to the analysis above.

For the sample before 1978 we find a significantly positive relation between the rate of signature collection and the probability of provoking a compromise. The effect is driven by cutoff counter proposals $(C P w)$; we find no significant effect for minor counter proposals (CPnw). The results are perfectly in line with our model, predicting that there is no incentive to over-collect when politicians deliberate about a minor counter proposal.

For the sample since 1978 no significant relation between signatures and counter proposals whatsoever can be detected. The result is consistent with the insignificant link between signatures

and the probability of reform: the restricted signature collection after 1978 reduces the usage of signatures as information channel for politicians to determine whether an initiative constitutes a threat to the current policy. 
Table 3: Effect of Collection Rate on Counter Proposals Before 1978

\begin{tabular}{|c|c|c|c|c|c|c|c|c|c|c|c|c|}
\hline Dep. var. & $\begin{array}{c}(1) \\
(\mathrm{CP}) \\
\end{array}$ & $\begin{array}{c}(2) \\
(\mathrm{CP}) \\
\end{array}$ & $\begin{array}{c}(3) \\
(\mathrm{CP}) \\
\end{array}$ & $\begin{array}{c}(4) \\
(\mathrm{CP}) \\
\end{array}$ & $\begin{array}{c}(5) \\
(\mathrm{CPw})\end{array}$ & $\begin{array}{c}(6) \\
(\mathrm{CPw}) \\
\end{array}$ & $\begin{array}{c}(7) \\
(\mathrm{CPw})\end{array}$ & $\begin{array}{c}(8) \\
(\mathrm{CPw}) \\
\end{array}$ & $\begin{array}{c}(9) \\
\text { (CPnw) }\end{array}$ & $\begin{array}{c}(10) \\
\text { (CPnw) }\end{array}$ & $\begin{array}{c}(11) \\
\text { (CPnw) }\end{array}$ & $\begin{array}{c}(12) \\
\text { (CPnw) }\end{array}$ \\
\hline Rate & $\begin{array}{c}0.022^{* * *} \\
(0.008)\end{array}$ & $\begin{array}{c}0.021^{* *} \\
(0.009)\end{array}$ & $\begin{array}{c}0.023^{* * *} \\
(0.007)\end{array}$ & $\begin{array}{c}0.026^{* * *} \\
(0.007)\end{array}$ & $\begin{array}{c}0.025^{* * *} \\
(0.007)\end{array}$ & $\begin{array}{c}0.021^{* * *} * \\
(0.008)\end{array}$ & $\begin{array}{c}0.027^{* * *} \\
(0.006)\end{array}$ & $\begin{array}{c}0.027^{* * *} \\
(0.006)\end{array}$ & $\begin{array}{c}-0.001 \\
(0.011)\end{array}$ & $\begin{array}{c}0.003 \\
(0.010)\end{array}$ & $\begin{array}{c}-0.004 \\
(0.011)\end{array}$ & $\begin{array}{c}0.001 \\
(0.010)\end{array}$ \\
\hline Observations & 115 & 115 & 115 & 115 & 101 & 101 & 101 & 101 & 83 & 83 & 83 & 83 \\
\hline Period FE & no & yes & no & yes & no & yes & no & yes & no & yes & no & yes \\
\hline Controls & no & no & yes & yes & no & no & yes & yes & no & no & yes & yes \\
\hline
\end{tabular}

Note: ${ }^{* * *} \mathrm{p}<0.01,{ }^{*} \mathrm{p}<0.05,{ }^{*} \mathrm{p}<0.1$. Probit regressions, marginal effects reported. Standard errors in brackets. Dependent variable is dummy for profile $(C P w)$ in columns 1-4, and profile $(C P n w)$ in columns 5-8. Observations from profile $(C P n w)$ are dropped in columns 1-4, and from profile $(C P w)$ in columns 5-8. Speed is defined as $\frac{\text { Signatures } / 100}{\text { Days }}$. Controls: Party $=1$ for initiatives proposed by parties. Experienced petitioners petitioners are Experienced $=1$. Economic $=1$ for economically framed initiatives. Period fixed effects are based on 6 institutional periods.

Table 4: Effect of Collection Rate on Counter Proposals since 1978

\begin{tabular}{|c|c|c|c|c|c|c|c|c|c|c|c|c|}
\hline Dep. var. & $\begin{array}{c}(1) \\
(\mathrm{CP})\end{array}$ & $\begin{array}{c}(2) \\
(\mathrm{CP})\end{array}$ & $\begin{array}{c}(3) \\
(\mathrm{CP})\end{array}$ & $\begin{array}{c}(4) \\
(\mathrm{CP})\end{array}$ & $\begin{array}{c}(5) \\
(\mathrm{CPw})\end{array}$ & $\begin{array}{c}(6) \\
(\mathrm{CPw})\end{array}$ & $\begin{array}{c}(7) \\
(\mathrm{CPw})\end{array}$ & $\begin{array}{c}(8) \\
(\mathrm{CPw})\end{array}$ & $\begin{array}{c}(9) \\
(\mathrm{CPnw})\end{array}$ & $\begin{array}{c}(10) \\
\text { (CPnw) }\end{array}$ & $\begin{array}{c}(11) \\
\text { (CPnw) }\end{array}$ & $\begin{array}{c}(12) \\
\text { (CPnw) }\end{array}$ \\
\hline Rate & $\begin{array}{c}0.005 \\
(0.007)\end{array}$ & $\begin{array}{c}0.006 \\
(0.007)\end{array}$ & $\begin{array}{c}0.002 \\
(0.007)\end{array}$ & $\begin{array}{c}0.003 \\
(0.007)\end{array}$ & $\begin{array}{c}0.002 \\
(0.005)\end{array}$ & $\begin{array}{c}0.003 \\
(0.005)\end{array}$ & $\begin{array}{l}-0.003 \\
(0.007)\end{array}$ & $\begin{array}{c}-0.003 \\
(0.007)\end{array}$ & $\begin{array}{c}0.003 \\
(0.004)\end{array}$ & $\begin{array}{c}0.004 \\
(0.004)\end{array}$ & $\begin{array}{c}0.006 \\
(0.004)\end{array}$ & $\begin{array}{c}0.007 \\
(0.004)\end{array}$ \\
\hline Observations & 134 & 134 & 134 & 134 & 121 & 121 & 99 & 99 & 112 & 112 & 112 & 112 \\
\hline Period FE & no & yes & no & yes & no & yes & no & yes & no & yes & no & yes \\
\hline Controls & no & no & yes & yes & no & no & yes & yes & no & no & yes & yes \\
\hline
\end{tabular}

Note: ${ }^{* * *} \mathrm{p}<0.01,{ }^{*} \mathrm{p}<0.05,{ }^{*} \mathrm{p}<0.1$. Probit regressions, marginal effects reported. Standard errors in brackets. Dependent variable is dummy for profile $(C P w)$ in columns 1-4, and profile $(C P n w)$ in columns 5 -8. Observations from profile $(C P n w)$ are dropped in columns 1-4, and from profile $(C P w)$ in columns 5-8. Speed is defined as $\frac{\text { Signatures } / 100}{\text { Days }}$. Controls: Party $=1$ for initiatives proposed by parties. Experienced petitioners petitioners are Experienced $=1$. Economic $=1$ for economically framed initiatives. Period fixed effects are based on 6 institutional periods. 


\subsection{Probability of Amending the Status Quo through Counter Proposals}

Hypothesis 3 (Status Quo) states that change is most likely after a counter proposal. As descriptive evidence, we report the number of initiatives and shares per observed profile by winning policy in Table 5. In total (column 5), the status quo prevails prevails most likely (68.3\%). The initiative wins with a probability of merely $7.2 \%$. In $24.5 \%$ of all cases, the counter proposal was adopted.

In ballots between status quo and initiative, the status quo wins in $90.3 \%$ of the cases (column 1 ). The initiative itself thus has a very low winning probability. Reform is much more likely once a counter proposal is made: the status quo remains in only $37.0 \%$ (without withdrawal, column 2) and $11.1 \%$ (withdrawal, column 3) of the cases respectively. By definition the status quo always stays in place if the initiative is withdrawn and has not generated a counter proposal (column 4).

Regression results confirm the tentative conclusions from the descriptive analysis. Tables 6 and 7 show the results before and since 1978. In columns (1) to (4) we aggregate all counter proposals in the variable $C P$. Counter proposals are split into the respective profiles $(n C P w)$ and $(n C P w)$ in columns (5) to (8).

The coefficients of counter proposals are positive and highly significant in all time periods. On average, initiatives provoking counter proposals are around 43 percentage points more likely to lead to reform in the pre-1978 period. Afterwards the effect varies between 47 and 61 percentage points depending on the specification.

Cutoff counter proposal are more likely to amend the status quo than minor counter proposals. The disaggregation reveals that a larger share of the effect runs through cutoff counter proposals $(C P w)$ than minor counter proposals. Indirect (i.e., non-constitutional) counter proposals might play a role in explaining this result. $51.85 \%$ of counter proposals are indirect ones, after which initiatives tend to be withdrawn and the legislation implemented mostly without vote (80.95\%). Indirect counter proposal thus very likely lead to reform. In contrast, direct (constitutional) counter proposals are relatively evenly spread among withdrawn (55.55\%) and not withdrawn initiatives.

Table 5: Winning Policy By Profile

\begin{tabular}{cccccc}
\hline & $(\mathrm{nCPnw})$ & $(\mathrm{CPw})$ & $(\mathrm{CPnw})$ & $(\mathrm{nCPw})$ & Total \\
& $(1)$ & $(2)$ & $(3)$ & $(4)$ & $(5)$ \\
\hline Q wins & 131 & 6 & 10 & 23 & 170 \\
& $(90.34)$ & $(11.11)$ & $(37.04)$ & $(100)$ & $(68.27)$ \\
CP wins & - & 48 & 13 & - & 61 \\
& - & $(88.89)$ & $(48.15)$ & - & $(24.5)$ \\
I wins & 14 & - & 4 & - & 18 \\
& $(9.66)$ & - & $(14.81)$ & - & $(7.23)$ \\
\hline Total & 145 & 27 & 54 & 23 & 249 \\
\hline
\end{tabular}

Note: The table shows the number of initiatives by winning policy and profile. Percentages are in brackets. 
Table 6: Probability of Amending the Status Quo Before 1978

\begin{tabular}{lcccccccc}
\hline & $(1)$ & $(2)$ & $(3)$ & $(4)$ & $(5)$ & $(6)$ & $(7)$ & $(8)$ \\
\hline $\mathrm{CP}$ & $0.427^{* * *}$ & $0.430^{* * *}$ & $0.434^{* * *}$ & $0.434^{* * *}$ & & & & \\
\\
$\mathrm{CPw}$ & $(0.030)$ & $(0.036)$ & $(0.039)$ & $(0.042)$ & & & & \\
& & & & & $0.457^{* * *}$ & $0.458^{* * *}$ & $0.470^{* * *}$ & $0.469^{* * *}$ \\
$\mathrm{CPnw}$ & & & & & $(0.048)$ & $(0.053)$ & $(0.059)$ & $(0.062)$ \\
& & & & & $0.373^{* * *}$ & $0.375^{* * *}$ & $0.379^{* * *}$ & $0.376^{* * *}$ \\
& & & & & $(0.070)$ & $(0.069)$ & $(0.073)$ & $(0.071)$ \\
\hline Observations & 226 & 226 & 226 & 226 & 226 & 226 & 226 & 226 \\
Period FE & no & yes & no & yes & no & yes & no & yes \\
Controls & no & no & yes & yes & no & no & yes & yes \\
\hline
\end{tabular}

Note: ${ }^{* * *} \mathrm{p}<0.01,{ }^{* *} \mathrm{p}<0.05,{ }^{*} \mathrm{p}<0.1$. Probit regressions, marginal effects reported. Standard errors in brackets. Dependent variable: dummy is 1 if status quo was amended. Observations with profile $(n C P w)$ are dropped because they predict initiative failure perfectly. Controls: Party $=1$ for initiatives proposed by parties. Experienced petitioners petitioners are Experienced $=1$. Economic $=1$ for economically framed initiatives. Period fixed effects are based on 6 institutional periods.

Table 7: Probability of Amending the Status Quo since 1978

\begin{tabular}{lcccccccc}
\hline & $(1)$ & $(2)$ & $(3)$ & $(4)$ & $(5)$ & $(6)$ & $(7)$ & $(8)$ \\
\hline $\mathrm{CP}$ & $0.468^{* * *}$ & $0.549^{* * *}$ & $0.482^{* * *}$ & $0.608^{* * *}$ & & & & \\
& $(0.019)$ & $(0.067)$ & $(0.038)$ & $(0.082)$ & & & & \\
$\mathrm{CPw}$ & & & & & $0.530^{* * *}$ & $0.572^{* * *}$ & $0.565^{* * *}$ & $0.633^{* * *}$ \\
& & & & & $(0.046)$ & $(0.067)$ & $(0.061)$ & $(0.083)$ \\
$\mathrm{CPnw}$ & & & & & $0.275^{* * *}$ & $0.379^{* * *}$ & $0.306^{* * *}$ & $0.438^{* * *}$ \\
& & & & & $(0.067)$ & $(0.072)$ & $(0.068)$ & $(0.082)$ \\
\hline Observations & 106 & 106 & 106 & 106 & 106 & 106 & 106 & 106 \\
Period FE & no & yes & no & yes & no & yes & no & yes \\
Controls & no & no & yes & yes & no & no & yes & yes \\
\hline
\end{tabular}

Note: ${ }^{* * *} \mathrm{p}<0.01,{ }^{* *} \mathrm{p}<0.05,{ }^{*} \mathrm{p}<0.1$. Probit regressions, marginal effects reported. Standard errors in brackets. Dependent variable: dummy is 1 if status quo was amended. Observations with profile $(n C P w)$ are dropped because they predict initiative failure perfectly. Controls: Party $=1$ for initiatives proposed by parties. Experienced petitioners petitioners are Experienced $=1$. Economic $=1$ for economically framed initiatives. Period fixed effects are based on 6 institutional periods.

We estimate an interacted model with indirect counter proposals. ${ }^{28}$ Though positive and jointly significant, the interaction between cutoff counter proposals and indirect counter proposals is insignificant. The latter are thus not driving the significant effect of cutoff counter proposals on the probability of reform.

We find supportive evidence for Hypothesis 3 (Status Quo) that reform is more likely if a counter

\footnotetext{
${ }^{28}$ First, we rerun the baseline regression with OLS to make sure the significance is robust to the linear estimator. Afterwards we include a dummy for indirect counter proposals and the interaction with cutoff counter proposals $(C P w)$.
} 
proposal is made. Additionally, we show that reform is more likely after a generous compromise that made the initiative withdraw as compared to a counter proposals after which the initiative is still running for ballot. This relation holds throughout the sampling period, it does not only depend on whether the signature collection process is informative or not.

\section{Concluding Remarks}

We presented a popular initiative model under uncertainty about the initiative's success in which petitioners collect signatures, politicians decide about making a counter proposal and the petitioners decide whether to withdraw the initiative or not. The model can rationalize the number of signatures collected as well as incentives to over-collect, why counter proposals are made and under which conditions the initiative is withdrawn. Moreover, it enables predictions about the probability that the status quo policy is amended, and the initiative is able to break the agenda setting monopoly of the politicians. We generally find supportive evidence for the mechanisms predicted by the model.

Reaching a counter proposal is the main channel for an initiative to shape politics and to make policy deviate from the status quo. The chance for policy change is higher in the case of farreaching political compromise that makes petitioners withdraw the initiative. The credible threat of a pending popular initiative mobilizes politicians to deviate from the previous status quo to some extent. The decision whether to issue a counter proposal or not is influenced by the perceived popularity of the initiative. Minor counter proposals are associated with a higher probability of policy change as well, but to a lesser extent, since in some cases, initiative and counter proposal are competing for votes in favor of a policy change.

The data suggest that when politicians decide whether to make a counter proposal or not, collecting signatures quickly plays a role in the decision. Faster collectors are associated with a higher

probability of establishing a counter proposal but only when collection time is unrestricted. The institutional change capping collection to 18 months diminished the possibility to derive information from the signature collection process. At the same time, a higher signature requirement most likely changed the composition of initiatives qualifying: the higher expected signature collection cost, the higher the expected payoff and thus ex ante winning probability must be for petitioners to commence collection. Our research is thus also relevant to questions of how institutional changes affect the initiative process and its outcome. 


\section{A Proofs}

\section{Proof of Winning Probability Counter Proposal}

Proof. The proof is laid out in two steps. We first show that for a given $x_{c}$ there exists an interval $\left[\underline{b}_{c}, \bar{b}_{c}\right] \subset\left[\frac{1}{2}\left(x_{q}+x_{c}\right), \frac{1}{2}\left(x_{c}+x_{i}\right)\right]$ with length $b_{c}=\bar{b}_{c}-\underline{b}_{c}$ in which $x_{c}$ receives more than half of the votes. Second, we show that $b_{c}=b$ for all $x_{c} \in\left(x_{q}, x_{i}\right)$, and the expected vote share is identical for all $x_{c} \in\left(x_{q}, x_{i}\right)$.

For a given $x_{c} \in\left(x_{q}, x_{i}\right)$, the vote share for a given realization of the median $m$ is $v_{c}^{m}\left(x_{q}, x_{c}, x_{i}\right)=$ $F_{m}\left(\frac{1}{2}\left(x_{c}+x_{i}\right)\right)-F_{m}\left(\frac{1}{2}\left(x_{q}+x_{c}\right)\right)$. By symmetry and single-peakedness of the density function of $F_{m}$ it is obvious that for a given $x_{c}$ the vote share is maximized when the median sits in the middle of $\left(\frac{1}{2}\left(x_{q}+x_{c}\right), \frac{1}{2}\left(x_{c}+x_{i}\right)\right)$. Let $\widehat{m}_{c}$ denote this point. If $x_{c}$ has $\pi_{c}\left(x_{q}, x_{c}, x_{i}\right)>0$, then $v_{c}^{\widehat{m}_{c}}\left(x_{q}, x_{c}, x_{i}\right)>\frac{1}{2}$, the vote share at the vote maximizing $m=\widehat{m}_{c}$ must be strictly larger than one half (if the vote share is below half at this point, the winning probability is zero for all $x_{c}$ ). Vote shares for symmetric $m=\widehat{m}_{c}-\delta$ and $m=\widehat{m}_{c}+\delta$ are identical. Note further that $v_{c}^{\widehat{m}}\left(x_{q}, x_{c}, x_{i}\right)$ at $m=\frac{1}{2}\left(x_{q}+x_{c}\right)$ (and $\left.m=\frac{1}{2}\left(x_{c}+x_{i}\right)\right)$ are at most 0.5 such that $x_{c}$ would loose with certainty for these median realizations. It follows that there exists a symmetric interval $\left[\underline{b}_{c}, \bar{b}_{c}\right]$ around $m=\widehat{m}$ that has a vote share larger than $\frac{1}{2}$ and thus positive winning probability.

The interval $\left(\frac{1}{2}\left(x_{q}+x_{c}\right), \frac{1}{2}\left(x_{c}+x_{i}\right)\right)$ in which realizations of $m$ make $x_{c}$ potentially win has length $b<\frac{1}{2}\left(x_{i}-x_{q}\right) \forall x_{c} \in\left(x_{q}, x_{i}\right)$. Also vote shares $v_{c}^{\widehat{m}_{c}}\left(x_{q}, x_{c}, x_{i}\right)=v_{c}^{\widehat{m}}\left(x_{q}, x_{c}, x_{i}\right)$ are identical for all $x_{c} \in\left(x_{q}, x_{i}\right)$. From this it follows that $b_{c}=\bar{b}-\underline{b}=b \forall x_{c} \in\left(x_{q}, x_{i}\right)$, and consequently $\pi_{c}\left(x_{q}, x_{c}, x_{i}\right)=\operatorname{Prob}(\underline{b} \leq m \leq \bar{b})=\frac{b}{\bar{\mu}-\underline{\mu}} \forall x_{c} \in\left(x_{q}, x_{i}\right)$ which concludes the proof.

\section{Proof of Proposition 1 (Equilibrium Petitioners)}

Proof. The proof proceeds by first establishing that petitioners' difference in expected payoffs between withdrawing and not withdrawing the initiative after a counter proposal is a quadratic function of $x_{c}$. Second, we show that the minimum of the parabola is right to $x_{i}$, such that the function is monotonically decreasing in $x_{c}$ over the relevant range $\left(x_{q}, x_{i}\right)$. We then establish conditions, such that petitioners prefer not to withdraw the initiative for counter proposals close to the status quo and vice versa for counter proposals close to the initiative. Since the payoff difference is monotonically decreasing in $x_{c}$, this proves the existence of a cutoff counter proposal above which the initiative is withdrawn.

Solving the optimal withdrawal problem yields a quadratic function of $x_{c}$ such that petitioners prefer to withdraw the initiative if:

$$
\frac{1}{2} x_{c}^{2}-\left[\bar{\mu}+\frac{1}{2}\left(x_{i}-x_{q}\right)-b\right] x_{c}<\left[b-\frac{1}{2}\left(x_{i}-x_{q}\right)\right] x_{q}+\left(\frac{1}{2} x_{i}-\bar{\mu}\right) x_{i}+k
$$

Taking the first derivative with respect to $x_{c}$ and setting it to zero yields the minimum of the left-hand side, $x_{c}^{*}=\mu+\frac{1}{2}\left(x_{i}-x_{q}\right)-b>0$. Then $x_{i}<x_{c}^{*}$ as long as $\bar{\mu}>x_{i}$. Plugging $x_{c}=x_{q}$ into equation (7), yields that the expected payoff from not withdrawing after the counter 
proposal is larger than from withdrawing, whenever $\pi_{i}\left(x_{q}, x_{i}\right) U_{i}^{B}>\kappa$. This is the condition such that petitioners strictly prefer the ballot to withdrawing the initiative without counter proposal. Plugging $x_{c}=x_{i}$ into equation (7) yields the the expected payoff from withdrawing the initiative is larger than without withdrawing whenever $k>\left[\frac{1}{2}\left(x_{q}+x_{i}\right)-b\right]\left(x_{i}-x_{q}\right)<0$, which is always true. Due to monotonicity there exists a cutoff counter proposal $\bar{x}_{c}$ that characterizes the petitioners' optimal withdrawal strategy.

\section{Proof of Proposition 2 (Counter Proposal Politicians)}

Proof. We proceed by first considering two lemmas from which the proof directly follows.

Lemma 1 Politicians never have an incentive to make a more favorable counter proposal than the cutoff $x_{c}^{\prime}>\bar{x}_{c}$.

Taking the first derivative of the expected payoff of an initiative that is withdrawn after a counter proposal, $P_{A}\left(x_{c} \geq \bar{x}_{c}\right)$, with respect to $x_{c}$, yields $\frac{\partial(\cdot)}{\partial x_{c}}=\frac{1}{\bar{\mu}-\mu}\left[\frac{1}{2} x_{c}-\bar{\mu}-\frac{1}{2} r\right]<0$ because $\frac{1}{2} x_{c}<\bar{\mu}$. Thus, the higher $x_{c}$, the lower is the expected payoff. Thus, politicians never make a counter proposal above the cutoff $\bar{x}_{c}$.

Lemma 2 If reputation costs $r$ are sufficiently large, there exists a counter proposal $x_{c}^{\prime \prime}=x_{q}+\epsilon<$ $\bar{x}_{c}, \epsilon \rightarrow 0$ which is preferred to the cutoff $\bar{x}_{c}$.

Suppose $x_{c}^{\prime \prime}=x_{q}+\epsilon<\bar{x}_{c}, \epsilon>0$ yields a higher payoff to politicians than $x_{c}=\bar{x}_{c}$. Then

$$
\begin{aligned}
\pi_{q}\left(x_{q}, x_{c}{ }^{\prime \prime}, x_{i}\right)\left(U_{q}^{A}-r\right)+ & \pi_{c}\left(x_{q}, x_{c}{ }^{\prime \prime}, x_{i}\right) U_{c}^{A}\left(x_{c}{ }^{\prime \prime}\right)+\pi_{i}\left(x_{q}, x_{c}{ }^{\prime \prime}, x_{i}\right) U_{i}^{A} \\
& >\pi_{c}\left(x_{q}, \bar{x}_{c}\right)\left(U_{q}^{A}-r\right)+\pi_{c}\left(x_{q}, \bar{x}_{c}\right) U_{c}^{A}\left(\bar{x}_{c}\right)
\end{aligned}
$$

Taking the derivative of the left-hand side with respect to $x_{c}{ }^{\prime \prime}$, yields a negative number whenever reputation costs $r>x_{i}-x_{q}-2 b$. We impose this condition since we assume that politicians do not make counter proposals just stealing votes from the initiative. Thus, the smaller $x_{c}{ }^{\prime \prime}$ (and hence $\epsilon$ ), the larger the left-hand side of (8). It is therefore maximized for $\epsilon \rightarrow 0$. Solving the above inequality (8) for $\epsilon$, letting it converge to zero, we have to show that $\epsilon$ can be positive for the existence of $x_{c}^{\prime \prime}$. Solving for $r$ yields an inequality depending on the sign of the term $b-\frac{1}{2}\left(x_{i}-\bar{x}_{c}\right)$ which depends on the status quo's winning probabilities when voted against both kinds of counter proposals after which the initiative is (not) withdrawn. It is straightforward to show that $b-\frac{1}{2}\left(x_{i}-\bar{x}_{c}\right)>0$ if $\pi_{q}\left(x_{q}, \bar{x}_{c}\right)>\pi_{q}\left(x_{q}, x_{c}^{\prime \prime}, x_{i}\right)$. I.e., the status quo wins more likely when the initiative is withdrawn. Then the solution is:

$$
\bar{r}=\left(x_{i}-\bar{x}_{c}\right) \frac{\bar{\mu}-\frac{1}{2}\left(x_{i}+\bar{x}_{c}\right)}{b-\frac{1}{2}\left(x_{i}-\bar{x}_{c}\right)}<r
$$

This is the sufficient condition to guarantee the existence of $x_{c}^{\prime \prime}=x_{q}+\epsilon<\bar{x}_{c}, \epsilon \rightarrow 0$ which makes politicians better off than proposing the cutoff $\bar{x}_{c}$. The converse is true if $\pi_{q}\left(x_{q}, \bar{x}_{c}\right)<\pi_{q}\left(x_{q}, x_{c}^{\prime \prime}, x_{i}\right)$ 
and consequently $b-\frac{1}{2}\left(x_{i}-\bar{x}_{c}\right)<0$ such that the inequality sign in 9 would reverse. Hence, equilibrium conditions would switch such that politicians would choose between $x_{c}^{*}=\varnothing$ and $x_{c}^{*}=x_{c}^{\prime \prime}$ if $r<\bar{r}$. Other than that, the model remains unaffected. For the remainder of the model, we assume that $\pi_{q}\left(x_{q}, \bar{x}_{c}\right)>\pi_{q}\left(x_{q}, x_{q}+\epsilon, x_{i}\right)$.

\section{Proof of Proposition 3 (Equilibrium Politicians)}

Proof. The politicians' optimal choice between $x_{c}^{*}=\bar{x}_{c}$ and $x_{c}^{*}=\varnothing$ is:

$$
x_{c}^{*}(\underline{\mu} \mid r \leq \bar{r})= \begin{cases}\varnothing \quad & \text { if } \pi_{q}\left(x_{q}, x_{i}\right) U_{q}^{A}+\pi_{i}\left(x_{q}, x_{i}\right) U_{i}^{A} \\ & >\pi_{q}\left(x_{q}, \bar{x}_{c}\right)\left(U_{q}^{A}-r\right)+\pi_{c}\left(x_{q}, \bar{x}_{c}\right) U_{c}^{A}\left(\bar{x}_{c}\right)-c \\ \bar{x}_{c} & \text { else }\end{cases}
$$

Their optimal choice between $x_{c}^{*}=\bar{q}+\epsilon$ and $x_{c}^{*}=\varnothing$ is:

$x_{c}^{*}(\underline{\mu} \mid r>\bar{r})= \begin{cases}\varnothing & \text { if } \pi_{q}\left(x_{q}, x_{i}\right) U_{q}^{A}+\pi_{i}\left(x_{q}, x_{i}\right) U_{i}^{A}> \\ & \pi_{q}\left(x_{q}, x_{c}^{\prime \prime}, x_{i}\right)\left(U_{q}^{A}-r\right)+\pi_{c}\left(x_{q}, x_{c}^{\prime \prime}, x_{i}\right) U_{c}^{A}\left(x_{c}^{\prime \prime}\right)+\pi_{i}\left(x_{q}, x_{c}^{\prime \prime}, x_{i}\right) U_{i}^{A}-c \\ x_{q}+\epsilon, \epsilon \rightarrow 0 \quad & \text { else }\end{cases}$

Politicians choose whichever action maximizes their expected payoff. We take the differences between the expected payoffs of the respective counter proposal and no counter proposal and take derivatives with respect to $\underline{\mu}$. We find that the payoff differences are monotony increasing in $\underline{\mu}$ and thus in the initiative's winning probability: the more likely the initiative wins, the higher is the expected payoff from making a counter proposal compared to making none. This proves that there exists a cutoff $\underline{\mu}^{c}$ above which counter proposals are made, and below which they are not. However, the cutoff $\underline{\mu}^{c}$ does not necessarily have to lie in the domain of $\underline{\mu} \in\left[0, x_{q}\right]$. The belief about $\underline{\mu}$ only plays a role for the politician's best action if the cutoff is located in the domain. This concludes the proof.

\section{Proof of Petitioners' Preference Ranking}

Proof. Petitioners' payoff from a vote of the initiative against the status quo taking into account that $U_{q}^{B}=0$ is

$$
\begin{aligned}
P_{B}\left(x_{c}^{*}=\varnothing\right) & =\pi_{q}\left(x_{q}, x_{i}\right) U_{q}^{B}+\pi_{i}\left(x_{q}, x_{i}\right) U_{i}^{B}-\kappa \\
& =\pi_{i}\left(x_{q}, x_{i}\right) U_{i}^{B}-\kappa
\end{aligned}
$$

Petitioners' payoff from a vote of the initiative against the cutoff counter proposal after which the 
initiative is withdrawn, taking into account that $U_{q}^{B}=0$, is

$$
\begin{aligned}
P_{B}\left(x_{c}^{*}=\bar{x}_{c}\right) & =\pi_{q}\left(x_{q}, \bar{x}_{c}\right) U_{q}^{B}+\pi_{c}\left(x_{q}, \bar{x}_{c}\right) U_{c}^{B}\left(\bar{x}_{c}\right) \\
& =\pi_{c}\left(x_{q}, \bar{x}_{c}\right) U_{c}^{B}\left(\bar{x}_{c}\right)
\end{aligned}
$$

Petitioners' payoff from a vote of the initiative against the counter proposal after which the initiative is not withdrawn, taking into account that $U_{q}^{B}=0, x_{c}^{\prime \prime} \rightarrow x_{q}$ and $U_{c}^{B}\left(x_{c}^{\prime \prime}\right) \rightarrow U_{q}^{B}=0$, is

$$
\begin{aligned}
P_{B}\left(x_{c}^{*}=x_{c}^{\prime \prime}\right) & =\pi_{q}\left(x_{q}, x_{c}^{\prime \prime}, x_{i}\right) U_{q}^{B}+\pi_{c}\left(x_{q}, x_{c}^{\prime \prime}, x_{i}\right) U_{c}^{B}\left(x_{c}^{\prime \prime}\right)+\pi_{i}\left(x_{q}, x_{c}^{\prime \prime}, x_{i}\right) U_{i}^{B}-\kappa \\
& =\pi_{c}\left(x_{q}, x_{c}^{\prime \prime}, x_{i}\right) U_{c}^{B}\left(x_{c}^{\prime \prime}\right)+\pi_{i}\left(x_{q}, x_{c}^{\prime \prime}, x_{i}\right) U_{i}^{B}-\kappa \\
& =\pi_{i}\left(x_{q}, x_{q}, x_{i}\right) U_{i}^{B}-\kappa \\
& =\pi_{i}\left(x_{q}, x_{i}\right) U_{i}^{B}-\kappa
\end{aligned}
$$

We get that $P_{B}\left(x_{c}^{*}=x_{c}^{\prime \prime}\right)-P_{B}\left(x_{c}^{*}=\varnothing\right)=0$ such that petitioners are indifferent between receiving no counter proposal and the counter proposal after which they do not withdraw the initiative. This is very intuitive since the counter proposal is close to the status quo.

Taking the difference between the payoffs yields $P_{B}\left(x_{c}^{*}=\bar{x}_{c}\right)-P_{B}\left(x_{c}^{*}=\varnothing\right)=\frac{1}{2}\left(x_{i}-\bar{x}_{c}\right)\left(x_{i}-\right.$ $\left.x_{q}\right)+\pi\left(x_{q}, \bar{x}_{c}\right) U_{c}^{B}\left(\bar{x}_{c}\right)+\kappa>0$. Therefore, petitioners are better off if they receive the cutoff counter proposal than if they do not receive a counter proposal. Though the cutoff counter proposal yields lower utility than the initiative, it has a considerably higher winning probability. 


\section{B Data Appendix}

The data source for the main variables is the Swiss Federal Archive which collects the Federal Announcements issued by the Swiss Federal Chancellery. All information is available online from the home pages of the Swiss Federal Chancellery and the Swiss Federal Archive. The data can be accessed on the following home pages: for an overview with links to federal announcement of more recent initiatives $h t t p: / / w w w . a d m i n . c h / c h / d / p o r e / v i / v i s \_2 \_2 \_5 \_1 . h t m l$ (Swiss Federal Chancellery), and for all federal announcements http : //www.amtsdruckschriften.bar. admin.ch/showHierarchyContent.do (Swiss Federal Archive). Some of the data we collected have been assembled independently by swissvotes.ch (a project of the Institute of Political Science at the University of Bern, Switzerland, and the Année Politique Suisse). However, their database only comprises information on initiatives that have been voted on, and the most recent initiatives are not included. For validation of our data collection, we have compared our data with this dataset.

For the identity of the initiative committee, we rely on data provided by the Swiss Federal Chancellery (2013), and on complementary information in Hofer (2012). The Swiss Federal Chancellery (2013) recorded some petitioners as committees formed especially for the purpose of raising the initiative, so called "ad-hoc-committees". With additional context information in Hofer (2012), we are able to allocate 5 of these committees to the groups behind them. If the composition of the committee remains unclear, these committees are coded as inexperienced and not powerful. A detailed overview of all variables, their sources and short descriptions is given in Table 8 . 
Table 8: Overview of Variables and Data Sources

\begin{tabular}{|c|c|c|}
\hline Variable & Source $(\mathrm{s})$ & Description \\
\hline Counter proposal & Swiss Federal Chancellery (2013) & $\begin{array}{l}\text { Dummy variable whether any formal counter proposal was } \\
\text { made }\end{array}$ \\
\hline Direct counter proposal & Swiss Federal Chancellery (2013) & $\begin{array}{l}\text { Dummy variable whether formal direct counter proposal was } \\
\text { made }\end{array}$ \\
\hline Indirect counter proposal & Swiss Federal Chancellery (2013) & $\begin{array}{l}\text { Dummy variable whether formal indirect counter proposal was } \\
\text { made }\end{array}$ \\
\hline De facto counter proposal & Hofer (2012) & $\begin{array}{l}\text { Dummy variable whether informal, related policy compromise } \\
\text { was made }\end{array}$ \\
\hline Time points related to initiative & Swiss Federal Chancellery (2013) & $\begin{array}{l}\text { All time points of initiative process (begin of collection, sub- } \\
\text { mission, eventual withdrawal or official statement of non- } \\
\text { qualification, voting day, etc.) }\end{array}$ \\
\hline Voting combinations & Swiss Federal Chancellery (2013) & $\begin{array}{l}\text { Indicates which proposals were voted on, and what the final } \\
\text { voting outcome was }\end{array}$ \\
\hline Institutional conditions & $\begin{array}{l}\text { Hofer }(2012), \text { Swiss Federal Chan- } \\
\text { cellery (2013) }\end{array}$ & $\begin{array}{l}\text { Signature threshold, maximum collection time, female voting, } \\
\text { withdrawal regulations, tie-breaking question }\end{array}$ \\
\hline $\begin{array}{l}\text { Number of (valid and invalid) signa- } \\
\text { tures }\end{array}$ & Swiss Federal Chancellery (2013) & Number of signatures collected for all initiatives \\
\hline Form of initiative & Swiss Federal Chancellery (2013) & $\begin{array}{l}\text { Indicates whether initiative was a general suggestion or a for- } \\
\text { mulated constitutional article }\end{array}$ \\
\hline Initiative committee & $\begin{array}{l}\text { Swiss Federal Chancellery (2013), } \\
\text { Hofer (2012), Rohner (2012) }\end{array}$ & Type, experience and power of initiative committee \\
\hline Initiative topic & $\begin{array}{l}\text { Swiss Federal Chancellery (2013), } \\
\text { Hofer (2012), Rohner (2012) }\end{array}$ & $\begin{array}{l}\text { Topic of the issue in question (economic, ideological, state or- } \\
\text { der) }\end{array}$ \\
\hline $\begin{array}{l}\text { Voting recommendations for initia- } \\
\text { tives }\end{array}$ & Swiss Federal Chancellery (2013) & Recommendations of National and State Council on initiative \\
\hline
\end{tabular}

Note: This table provides an overview of the variables used in the empirical part with a short variable description, and the source from which it was retrieved. 


\section{Coding of Time Periods for Initiatives}

The allocation of initiatives into time periods takes into account the timing of the institutional changes and the relevant time points in the initiative process of each initiative.

1. Period 1 starts with the introduction of the popular initiative in 1891.

2. Period 2 begins when withdrawals of initiatives become a de-facto routine. The relevant time point is the time of withdrawal (30 October 1930) of the initiative that marks the beginning of more frequent withdrawals. All initiatives that passed the political discussion afterwards arguably face a different game setup. Fortunately, no initiatives were being dealt with at this point of time (the next initiative was only started in 1931 and all previous initiatives had already been voted upon).

3. Period 3 begins with the formal legalization of withdrawal clauses on 1 February 1951. The most relevant time point is the start of the signature collection (since legalized withdrawal clauses could be included in the initiative text). No initiatives were going through the signature collection process at this time, so coding is straightforward.

4. Period 4 starts when women were enfranchised to vote and allowed to sign popular initiatives as well on 16 March 1971. Since the main effect on our model comes from the doubled population of potential signers, all initiatives that were still at the signature collection stage at this point of time would have been affected by the change. By coincidence, there were again no initiatives at collection stage at this point in time, so there are no initiatives that were only partly affected by the change, and the assignment into period 4 is clear.

5. Period 5 starts when the signature requirement was doubled (on 27 December 1977) and a maximum time period for signature collection was introduced (on 1 July 1978). The time limit of 18 months was only a binding for initiatives handed in 18 months after the new law was in force. Thus, the two reforms came into force shortly after each other, but were not effective from exactly the same date. There was only one initiative which already had to collect 100,000 signatures but did not face the limit of 18 months. However, there was a de-facto limit for this initiative as well, as the old regulation phased out at some point of time. The initiative took slightly more than two years to collect the signatures. 16 days after the signatures were handed in, the old regulation phased out definitely. Thus, there was a de-facto limit of 26 months collection time (instead of 18 months afterwards), whereas there was no time limit at all for earlier initiatives. For that reason and because the signature requirement was already enhanced, we code the initiative as obeying to the new regulation. Apart from this special case, coding is straightforward.

6. The last period 6 starts when the tie-breaking question between counter proposal and initiative was introduced by popular vote on 5 April 1987. The relevant time point for an initiative to be affected by the new regulation is its date of ballot. 


\section{Comparative Statics}

In this additional section, we conduct a comparative statics analysis regarding the cost of signature collection, collection requirement, maximum collection time, and an alternative voting rule including a tie-breaking question. Afterwards, we test the model predictions based on large institutional changes: the enfranchisement of women in 1971, a doubling of the signature requirement paired with a collection time restriction, and a change in the voting rules. By testing theoretical implications, we checked the model for empirical plausibility, making use of major institutional changes in Switzerland over time.

\section{D.1 Institutional Changes}

The Swiss constitutional initiative at federal level was first introduced in 1891. Five major institutional changes to the initiative process lead to six regulatory periods as outlined in Table $9 .^{29}$

The "Early Period" (1891-1927) is marked by the lack of a formal clause that would have allowed petitioners to withdraw the initiative at any time. The first initiative was withdrawn in 1908, and it remained the only one until 1928.

The second period "De Facto Withdrawal" starts in 1928 when withdrawal of initiatives became more frequent after receiving a counter proposal, arguably out of political learning (Swiss Federal Chancellery, 2013). While this institutional change did not take place at a formally fixed date, the sudden start of withdrawals after 1928 is a clear change to the political game.

The "Formal Withdrawal" period 3 (1951-1970) begins in 1951 when initiative withdrawal was officially legalized conditional on all members of the initiative committee unanimously agreeing to withdraw (Hofer, 2012). This provision was relaxed in 1962 to two thirds of the committee, and further decreased to the absolute majority in 1978. We consider these adjustments in withdrawal rules as too small to define a new period.

The "Female Voting" period 4 (1971-1977) starts when women were enfranchised at federal level on 7 February 1971, giving them also further political rights like to sign initiative petitions.

Period 5 (1978-1986) begins when new "Collection Restrictions" were introduced as a consequence of female suffrage in 1978. First, the signature requirement was increased from 50,000 to 100,000 signatures. Second, a maximum of 18 months for signature collection was introduced (Hofer, 2012).

The sixth period "Tie-Break" (1987-2010) commences with a new voting rule for the case in which initiative and counter proposal are voted simultaneously. Before 1987 voters had to decide in favor of either the initiative or the counter proposal, or oppose both of them. Since April 1987 it is possible to vote in favor of both initiative and counter proposal. In a tie-breaking question, voters declare what alternative they prefer in case both proposals win a majority of votes.

\footnotetext{
${ }^{29}$ Other, though minor institutional changes include the creation of the $26^{\text {th }}$ Swiss canton Jura separating from the canton Bern in 1978, the introduction of cantonal postal voting between 1978 and 2005, and the reduction of voting age from 20 to 18 in 1991.
} 
Table 9: Overview of Main Institutional Changes

\begin{tabular}{lccl}
\hline & Period & Years & Subject of Reform \\
\hline 1 & Early Period & $1891-1927$ & No legal provision regarding initiative withdrawal \\
2 & De Facto Withdrawal & $1928-1951$ & $\begin{array}{l}\text { De-facto introduction of initiative withdrawal } \\
\text { Official formalization of possibility to withdraw if petitioners } \\
\text { agree unanimously }(2 / 3 \text { majority since 1962, absolute majority } \\
\text { Formal Withdrawal }\end{array} 1951-1970$ \\
4 & Female Voting & $1971-1977$ & $\begin{array}{l}\text { Introduction of female voting and political rights like initiative } \\
\text { signing }\end{array}$ \\
$5 \quad$ Collection Restrictions & $1978-1986$ & $\begin{array}{l}\text { Signature requirement doubled to 100,000, collection time re- } \\
\text { stricted to } 18 \text { months, mandatory withdrawal article, extension } \\
\text { of parliamentary discussion period to 4 years } \\
\text { Introduction of tie-breaking question when both initiative and } \\
\text { counter proposal are voted }\end{array}$ \\
\hline
\end{tabular}

Note: This table gives an overview of the 6 institutional periods, the relevant years and a short description of the main institutional changes defining the period.

\section{D.2 Equilibrium outcomes after institutional changes and hypotheses}

\section{Costs of Signature Collection}

When signature collection costs decrease, qualifying an initiative becomes relatively more attractive. As a consequence the number of initiatives entering the qualification stage increases, and the mix of initiatives changes: the new initiatives have lower expected payoffs due to lower expected winning probabilities of the initiative. In expectation, decreasing collection costs thus increases the share of low type initiatives that are less likely to receive a counter proposal. From Hypothesis 3 (Status Quo) we know that a lower probability of counter proposal decreases the probability of reform. We should expect the status quo to win more often.

Hypothesis 4 (Signature Collection Costs) Lower signature collection costs $\gamma$ lead to an increase in the number of initiatives entering the qualification stage. In expectation, the share of low type initiatives increases. The probability of receiving a counter proposal and amending the status quo decreases.

\section{Collection Time Restriction}

In our model, collection time is not constrained. With a collection time restriction $t_{\max }=T$ initiatives do not qualify if petitioners are unable to collect the signature requirement sufficiently quickly. In expectation, low types are slower collectors such that initiatives with low winning probabilities are less likely to qualify for ballot. Since the expected payoff from not qualifying an initiative is negative - the status quo remains and collection costs accrue - we should observe fewer low types entering the qualification stage, and some initiatives not qualifying even though they begin collecting. This leads to a higher share of counter proposals and a higher probability of reform. 
Hypothesis 5 (Collection Time Restriction) As a consequence of restricted collection time some initiatives do not qualify, the overall number of initiatives starting signature collection decreases. On average, the share of counter proposals increases, and reform becomes more likely.

\section{Signature Requirement}

A higher signature requirement forces petitioners to spend more time collecting signatures leading to higher collection costs. Petitioners with low expected payoffs might therefore choose not to begin with signature collection in the first place. In expectation the number of initiatives decreases and the share of high types increases. Intuitively, with a higher signature requirement politicians observe the signature collection process for a longer time and wait if a high lump sum is realized. Eventually, they are more certain about the initiative's type. Since high types are more likely to receive a counter proposal, the share of initiatives with counter proposals increases, and reform becomes more likely.

Hypothesis 6 (Signature Requirement) Increasing the signature requirement $\bar{s}$ renders qualification more costly. On average fewer initiatives begin collection, the shares of initiatives receiving a counter proposal as well as the probability of amending the status quo increase.

The model predicts that both the increase in $\bar{s}$ and the time restriction lead to a reduction in the number of initiatives and to higher shares of high type initiatives, thus more counter proposals and more reforms. However, only the collection time restriction makes some initiatives not qualify.

\section{D.3 Estimation and Data}

To test Hypotheses 4 to 6 concerning signature collection costs, collection time restriction, and signature requirement, we use three institutional changes corresponding to different sets of model parameters. First, when women were enfranchised at federal level on 16 March 1971, they were also given the right to sign initiative petitions. As a consequence the pool of potential signers roughly doubled while leaving the signature requirement unchanged. Signature collection costs decreased discontinuously on that day. ${ }^{30}$ This allows us to test Hypothesis 4 (Signature Collection Costs) which predicts a decrease in the signature collection cost parameter $\gamma$.

Two important institutional changes occurred almost simultaneously in 1978: collection time was restricted to 18 months from previously no time constraint, and the signature requirement was increased from 50,000 to 100,000 signatures. We use these major changes to the initiative process to test Hypotheses 5 (Collection Time Restriction) and 6 (Signature Requirement) respectively. The time restriction introduces a cap for the signature collection time at $t_{\max }=T$ to the model, and

\footnotetext{
${ }^{30}$ Even if directly after their enfranchisement women were supposedly politically less active than their male counterparts (cf. Lott and Kenny (1999) for some evidence from the USA), the change in the electorate was large enough to expect an impact on the initiative process.
} 
the raise in the signature requirement corresponds to an increase in $\bar{s}$. Both institutional changes coincide and the two corresponding hypotheses are very similar. Consequently, the setup does not allow to disentangle both changes empirically, and we can only estimate the aggregate effect.

Institutional changes are not necessarily exogenous to the initiative process. The introduction of female voting rights, for example, not only reduced signature collection costs, but also changed the composition of the electorate. This can have two effects. First, it probably affects the kind of initiatives that are proposed. However, on average the initiative process takes 4.5 years such that this effect takes time to unfold. Second, voter preferences might be affected in general. Arguably the most likely exogenous change to the process was the increase in the signature requirement paired with the collection time restriction, since it was a belated adjustment to female franchise.

Each hypothesis makes predictions about the number of initiatives, the probability of receiving a counter proposal, and the probability of amending the status quo. We estimate the effect of above mentioned institutional changes on each of these outcomes. Let change $_{i p}$ denote a binary variable taking value 1 after the institutional change, and 0 before the change. The first estimation equation regarding the number of initiatives per year with intercept $\alpha$ and error term $\epsilon_{i p}$ is:

$$
\text { initiatives }_{i p}=\alpha+\beta \text { change }_{i p}+\epsilon_{i p}
$$

We use two dummies for the profiles including counter proposals $(C P w)$ and $(C P n w)$ to estimate the effect of the institutional change on the probability to receive a counter proposal. All initiatives without counter proposals serve as the reference category.

$$
C P_{i p}=\alpha+\beta_{1} \text { change }_{i p}+\epsilon_{i p}
$$

The effect of institutional change on the probability of reform is estimated using the simple regression

$$
\text { amended }_{i p}=\alpha+\beta_{1} \text { change }_{i p}+\epsilon_{i p}
$$

We use the same data of qualified initiatives as in the main paper. Additionally, for 77 not qualified initiatives we collected the titles, the dates of the beginning of signature collection and the date when non-qualification was officially communicated (Swiss Federal Chancellery, 2013). For each year we then calculated the number of successfully submitted initiatives as well as the number of initiatives not qualified.

For all estimations, we limit the sample to initiatives in the two periods adjacent to the institutional change. This weakens the influence of time trends and minor institutional changes, however, it does not completely exclude them. The coefficients identify the average change in the dependent variable after the institutional change. To estimate a causal effect, we obviously lack an untreated control group. For robustness, we estimate versions with initiatives in smaller, symmetric bins around the institutional change at the price of reducing the number of observations. We also run regressions including linear and quadratic time trends.

Table 10 summarizes the hypotheses and relates them to their institutional periods. 
Table 10: Overview of Hypotheses and Relevant Periods

\begin{tabular}{clll}
\hline Hypothesis & Affected Variables & Change & Institutional Periods \\
\hline 4 & $\begin{array}{l}\text { Decrease signature } \\
\text { collection costs } \gamma\end{array}$ & Female suffrage & 3: Formal Withdrawal \& 4: Female Voting \\
5 & $\begin{array}{l}\text { Maximum collection } \\
\text { time } T\end{array}$ & 18 months cap & 4: Female Suffrage \& 5: Collection Threshold \\
6 & $\begin{array}{l}\text { Signature require- } \\
\text { ment } \bar{s}\end{array}$ & 4: Female Suffrage \& 5: Collection Threshold \\
\hline
\end{tabular}

NotE: This table relates the hypothesis and affected model parameter to the institutional change as well as the periods used for the estimation.

\section{D.4 Results}

\section{Signature Collection Costs}

Hypothesis 4 (Signature Collection Costs) predicts more initiatives when the costs of qualifying an initiative drop. Initiatives under lower qualifying costs are more likely to be of low type and thus have a smaller likelihood to receive counter proposals and to amend the status quo. We compare the institutional periods before and after female suffrage. We observe 35 initiatives in the "Formal Withdrawal" period between 1951 and 1970, and 26 in the "Female Voting" period between 1971 and 1977. Of these initiatives 1 and 4, respectively, were withdrawn without receiving a counter proposal (profile $(n C P w)$ ).

Regression results are in Table 11. After female suffrage, the yearly number of initiatives submitted and qualified increases significantly by 2.4 (column 1), corresponding to more than a $100 \%$ increase in the yearly number of initiatives. The probability to receive a counter proposal which is satisfactory enough to make the initiative withdraw drops significantly by 40.1 percentage points. However, there is no significant change with respect to the share of counter proposals without withdrawal. The coefficient only turns significantly negative once we control for time trends. After the institutional change the probability of amending the status quo is significantly reduced by 36.3 percentage points (column 4). In accordance with our model, this reflects the increased share of low type initiatives receiving fewer counter proposals and consequently being less likely to lead to reform. Reducing the number of years around the institutional change to eight, the coefficients of the probability to receive counter proposals turn insignificant due to considerably fewer observations (all results on request.)

\section{Collection Time Constraint and Signature Requirement}

Hypotheses 5 (Collection Time Restriction) and 6 (Signature Requirement) predict that some initiatives are unsuccessful in qualifying the initiative, such that the share of high types receiving counter proposals and changing the status quo increases.

We focus on the periods "Female Voting" and "Collection Restrictions" adjacent to the change. 
Table 11: Signature Collection Costs

\begin{tabular}{|c|c|c|c|c|}
\hline Dep. var. & $\begin{array}{c}(1) \\
\text { initiatives p.a. }\end{array}$ & $\begin{array}{c}(2) \\
(\mathrm{CPw})\end{array}$ & $\begin{array}{c}(3) \\
(\mathrm{CPnw})\end{array}$ & $\begin{array}{c}(4) \\
\text { amended }\end{array}$ \\
\hline Change & $\begin{array}{c}2.350^{* * * *} \\
(0.798)\end{array}$ & $\begin{array}{c}-0.401^{* * *} \\
-0.093\end{array}$ & $\begin{array}{c}0.060 \\
-0.133\end{array}$ & $\begin{array}{c}0.363^{* * *} \\
-0.101\end{array}$ \\
\hline $\begin{array}{l}\mathrm{R}^{2} \\
\text { Observations }\end{array}$ & & $\begin{array}{c}0.147 \\
51\end{array}$ & $\begin{array}{c}0.004 \\
41\end{array}$ & \\
\hline \multicolumn{5}{|c|}{$\begin{array}{l}\text { Note: }{ }^{* * *} \mathrm{p}<0.01,{ }^{* *} \mathrm{p}<0.05,{ }^{*} \mathrm{p}<0.1 \text {. Results from ordinary least } \\
\text { squares regressions }(1) \text {. Probit regressions, marginal effects reported, } \\
\text { pseudo } \mathrm{R}^{2}(2-4) \text {. Standard errors in brackets. Dependent variables in } \\
\text { first row: initiatives p.a. are the average number of initiatives per year } \\
\text { in an institutional period. ( } C P w) \text { and }(C P n w) \text { are dummies for the } \\
\text { respective profile, amended is one if the status quo was amended. Es- } \\
\text { timates are based on observations from periods "Formal Withdrawal" } \\
\text { and "Female Voting". Observations from profile }(C P n w) \text { are dropped } \\
\text { in column } 2 \text {, from profile }(C P w) \text { in column } 3 \text {, and from profile }(n C P w) \\
\text { in column } 4 \text {. }\end{array}$} \\
\hline
\end{tabular}

During the period "Female Voting" (1971-1977) there are 26 qualified initiatives, and 23 in the following period "Collection Restrictions" (1978-1986). In total, there were 4 initiatives withdrawn without counter proposal before the change, and 2 thereafter (profile $(n C P w)$ ).

Regression results are in Table 12. The first prominent change in outcomes is that 11 initiatives (or 0.8 initiatives annually) did not qualify for ballot in the period after the institutional changes in 1978 due to not collecting enough signatures within the restricted time. In contrast, between 1891 and 1978 only two initiatives did not qualify for ballot. ${ }^{31}$ The number of annually qualified initiatives remains unchanged (columns 1 and 2).

The probability of receiving counter proposals $(C P w)$ and $(C P n w)$ increases. However, only the former is significant at conventional levels (column 3 and 4). There is a significant increase in the probability of amending the status quo by almost 30 percentage points (column 5) after the institutional changes. When accounting for time trends and initiatives closer to the institutional change, only the change in not qualified initiatives remains significant.

The data generally support Hypothesis 5 (Collection Time Restriction) regarding the number of initiatives and the probability of reform. However, we find only weak evidence for an increase in the probability of receiving counter proposals. Time trends seem to be important for the sampling period. This might be due to concurrent shifts in politics that are not accounted for in the model, or the strong population growth between 1971 and 1978 which further lowered the signature collection costs (Wili, 1982).

\footnotetext{
${ }^{31}$ These two cases occurred in 1894 ("Initiative for free healthcare and a monopoly on tobacco", which did not qualify because it collected too few signatures) and in 1922 ("Initiative for a reform of the federal administration, including federal railways" - this initiative did not qualify because of too many invalid signatures). Cf. Hofer (2012) for details.
} 
Table 12: Collection Time Constraint and Signature ReQUIREMENT

\begin{tabular}{lccccc}
\hline Dep. var. & $\begin{array}{c}(1) \\
\text { qualified } \\
\text { p.a. }\end{array}$ & $\begin{array}{c}(2) \\
\text { not quali- } \\
\text { fied p.a. }\end{array}$ & $\begin{array}{c}(3) \\
(\mathrm{CPw})\end{array}$ & $\begin{array}{c}(4) \\
(\mathrm{CPnw})\end{array}$ & $\begin{array}{c}(5) \\
\text { amended }\end{array}$ \\
\hline Change & 0.200 & $0.800^{* *}$ & $0.234^{*}$ & 0.093 & $0.280^{* *}$ \\
& $(1.257)$ & $(0.338)$ & $(0.121)$ & $(0.138)$ & $(0.116)$ \\
\hline $\mathrm{R}^{2}$ & -0.108 & 0.316 & 0.070 & 0.010 & 0.080 \\
Observations & 11 & 11 & 39 & 39 & 43 \\
\hline
\end{tabular}

Note: *** $\mathrm{p}<0.01,{ }^{* *} \mathrm{p}<0.05, * \mathrm{p}<0.1$. Results from ordinary least squares regressions (1-2). Probit regressions, marginal effects reported, pseudo $\mathrm{R}^{2}(3-5)$. Standard errors in brackets. Dependent variables in first row: (not)qualified p.a. are the average yearly number of initiatives (not) qualified. $(C P w)$ and $(C P n w)$ are dummies for the respective profile, amended is one if the status quo was amended. Estimates are based on observations from periods "Female Voting" and "Collection Restrictions". Observations from profile (CPnw) are dropped in column 3, from profile $(C P w)$ in column 4 , and from profile $(n C P w)$ in column 5 . 


\section{References}

Altman, David, Direct Democracy Worldwide, Cambridge: Cambridge University Press, 2010.

Association for More Democracy, Mehr Demokratie e.V., "www.mehr-demokratie.de," 2014.

Barankay, Iwan, Pascal Sciarini, and Alexander H. Trechsel, "Institutional Openness and the Use of Referendums and Popular Initiatives: Evidence from Swiss Cantons," Swiss Political Science Review, 2003, 9 (1), 169-199.

Black, Duncan, The Theory of Committees and Elections, Cambridge: Cambridge University Press, 1958.

Boehmke, Frederick J. and R. Michael Alvarez, "The Influence of Initiative Signature Gathering Campaigns on Political Participation," 2014.

Calvert, Randall L., "Robustness of the multidimensional voting model: candidate motivations, uncertainty, and convergence," Americal Journal of Political SciencePolitical Science, 1985, 29 (1), 69-95.

Center for Direct Democracy, Homepage of the Center for Direct Democracy, www.c2d.ch, 2014 .

Downs, Anthony, "An Economic Theory of Political Action in a Democracy," Journal of Political Economy, 1957, 65 (2), 135-150.

Fatke, Matthias and Markus Freitag, "Direct Democracy: Protest Catalyst or Protest Alternative?," Political Behavior, 2013, 35 (2), 237-260.

Fontana, Katharina, "Druck für eine strikte Umsetzung der Ausschaffungsinitiative," Neue Zürcher Zeitung, 2012. http ://www.nzz.ch/aktuell/schweiz/druck - fuer - eine - strikte umsetzung - der - ausschaf fungsinitiative - 1.17913532 .

Frey, Bruno S., "Direct Democracy : Politico-Economic Lessons from Swiss Experience," The American Economic Review, 1994, 84 (2), 338-342.

Gerber, Elisabeth R., "Legislative Response to the Threat of Popular Initiatives," American Journal of Political Science, 1996, 40 (1), 99-128.

- and Arthur Lupia, "Campaign Competition and Policy Responsiveness in Direct Legislation Elections," Political Behavior, 2010, 17 (3), 287-306.

Habermas, Juergen, Faktizitaet und Geltung, Frankfurt: Suhrkamp, 1992.

Hofer, Bruno, Volksinitiativen der Schweiz, One to One, 2012.

Initiative and Referendum Institute at the University of Southern California, Homepage of the Initiative and Referendum Institute, www.iandrinstitute.org, 2014. 
Jaronicki, Katharina E., "Campaigning in Direct Democracies: Initiative Petition Signing, Turnout, and Acceptance," 2013. University of St.Gallen Economics Working Paper Series, No. 1333.

Kartik, Navin and R. Preston McAfee, "Signaling character in electoral competition," The American Economic Review, 2007, 97 (3), 852-870.

Keller, R. Godfrey and Sven Rady, "Strategic Experimentation with Poisson Bandits," Theoretical Economics, 2010, 5, 275-311.

Kirchgässner, Gebard and Bruno S. Frey, Demokratische Wirtschaftspolitik, Vahlen, 2012.

Leduc, Lawrence, "Opinion Change and Voting Behavior in Referendums," European Journal of Political Research, 2003, 41 (6), 711-732.

Lott, John R. and Lawrence W. Kenny, "Did Women's Suffrage Change the Size and Scope of Government?," Journal of Political Economy, 1999, 107 (6), 1163-1198.

Mäder, Lukas, "Noch kaum Unterschriften für FDP-Initiative," 20 Minuten, 2010. http : //www.20min.ch/schweiz/news/story/14953477.

Matsusaka, John G., "Economics of Direct Legislation," Quarterly Journal of Economics, 1992, $107(2), 541-571$.

_ , "The Eclipse of Legislatures: Direct Democracy in the 21st Century," Public Choice, 2005, 124 (1), 157-177.

- and Nolan M. McCarty, "Political Resource Allocation: Benefits and Costs of Voter Initiatives," Journal of Law, Economics, \& Organizations, 2001, 17 (2), 413-448.

Neiman, Max and Mark Gottdiener, "The relevance of the qualifying stage of initiative politics: The case of petition signing," Social Science Quarterly, 1982, 63 (3), 582-588.

Osborne, Martin J., "Entry-Deterring Policy Differentiation by Electoral Candidates," Mathematical Social Sciences, 2000, (40), 41-62.

_ and Al Slivinski, "A Model of Political Competition with Citizen Candidates," Quarterly Journal of Economics, 1996, (111), 65-96.

Parry, Janine, Daniel Smith, and Shayne Henry, "The impact of petition signing on voter turnout," Political Behavior, 2012, 34, 117-136.

Rohner, Gabriela, Die Wirksamkeit von Volksinitiativen im Bund 1848-2010, Zurich: Schulthess, 2012.

Schaffner, David, "Streit beim Unterschriftensammeln für die Erbschaftssteuer-Initiative, 27.6.2012," Tages-Anzeiger, 2012. 
Schmid, Lukas, "Political Decisions in Multiple Referendums," 2013. University of St.Gallen, mimeo.

Strulovici, Bruno, "Learning While Voting: Determinants of Collective Experimentation," Econometrica, 2010, 78 (3), 933-971.

Swiss Federal Chancellery, "Chronology of popular initiatives," Homepage of the Swiss Federal Chancellery, www.bk.admin.ch, 2013.

Wili, Heinrich, "Befristung der Unterschriftensammlung und Eröhung der Unterschriftenzahlen bei Volksbegehren: Erste Bilanz ihrer Auswirkungen," in A. Meier-Hayoz, P. Dutoit, and Saladin. B., eds., Zeitschrift für Schweizerisches Recht, Basel: Helbling und Lichtenhahn, 1982, pp. 61-86.

Wittman, Donald, "Candidate Motivation: A Synthesis of Alternative Theories," American Political Science ReviewPolitical Science, 1983, 77 (1), 142-157. 